\title{
Seedling Resistance Genes to Leaf Rust in Soft Red Winter Wheat
}

\author{
Yeshi A. Wamishe and Eugene A. Milus, Department of Plant Pathology, University of Arkansas, Fayetteville 72701
}

\begin{abstract}
Wamishe, Y. A., and Milus, E. A. 2004. Seedling resistance genes to leaf rust in soft red winter wheat. Plant Dis. 88:136-146.

Seedling and adult-plant resistance have been used to manage leaf rust, caused by Puccinia triticina, but there is little information on resistance genes in contemporary cultivars and advanced breeding lines of soft red winter wheat (Triticum aestivum). Lack of information on the genetic basis for resistance leads to uncertainty about durability of resistance and makes pyramiding resistance genes more difficult. The objective of this study was to determine the genetic basis for race-specific seedling resistance to leaf rust among the 116 contemporary lines from the 1998-99 Arkansas Wheat Cultivar Performance Test and the Uniform Eastern and Southern Soft Red Winter Wheat Nurseries. To postulate the presence of genes for leaf rust resistance $(\mathrm{Lr}$ genes), seedlings of each line and 24 isolines in a Thatcher background were evaluated for infection type in growth chambers at $22 / 18^{\circ} \mathrm{C}$ (day/night) or constant 17 or $18^{\circ} \mathrm{C}$ using 22 races of $P$. triticina. A computer program was used to analyze infection type data and facilitate identification of $L r$ genes. Genes $L r 1,2 a, 2 c, 3,3 k a, 9,10,11,14 a, 18,20,23,24$, and 26 were identified among the lines tested. Genes Lr3, 10, and 11 were the most common. Genes Lr15, 28, and 30 were postulated as possibly present in some lines but were not likely to be important among the lines. Genes $\operatorname{Lr} 16,17,21,32,36,38$, and 39 were not detected. Fifty-four lines had one or more unidentified $L r$ genes that were not included in the set of 24 isolines. Only four lines (Agripro Marion, APD94-5282, NC94-7197, and VA97W-375) were resistant to all races used in this study, and these were postulated to have the combination of $\operatorname{Lr} 9,24$, and 26.
\end{abstract}

Additional keywords: gene-for-gene specificity

Leaf rust, caused by Puccinia triticina Eriks. (syn: Puccinia recondita Rob. ex. Desm. f. sp. tritici), is probably the most important and widespread disease of wheat (Triticum aestivum L.) (23,33). Leaf rust is adapted to a range of climates and occurs wherever wheat is grown (10). Yield loss estimates from leaf rust across all states that predominantly grow soft red winter wheat (Alabama, Arkansas, Florida, Georgia, Illinois, Indiana, Kentucky, Louisiana, Mississippi, Missouri, North Carolina, Ohio, South Carolina, Tennessee, and Virginia) averaged $1.2 \%$ (range $0.3 \%$ to $1.9 \%$ ) from 1997 to 2001 (16). The estimated losses from leaf rust during this period were more than 555,000 metric tons, representing a loss of more than $\$ 61,000,000$ to growers. Without resistant cultivars, the loss would have been much greater.

$P$. triticina has diverse virulence and the ability to overcome resistance genes. New races typically overcome resistance in winter wheat cultivars in a shorter period than resistance in spring wheat cultivars grown in the United States (12). The use of resistance against $P$. triticina has often

Corresponding author: Eugene A. Milus

E-mail: gmilus@uark.edu

Accepted for publication 27 August 2003.

Publication no. D-2003-1119-03R

(C) 2004 The American Phytopathological Society been a single gene at a time (30) and has largely depended on replacing resistance genes upon detection of virulent races (33). However, resistance that is based on a single gene can easily be overcome by a change in virulence at a single locus in the pathogen (9). With a limited number of resistance genes in hexaploid wheat $(22,36)$, and with the difficulties and associated problems of transferring genes from related species through traditional breeding, combinations of genes are believed to provide longer lasting resistance to leaf rust than single genes (30).

Genetic interactions between wheat and $P$. triticina have been shown to operate in a gene-for-gene relationship (32). Gene postulation applies the principles of gene-forgene specificity to determine the most probable resistance genes present in host lines (12). Resistance genes can be identified based on the infection type expressed on the host when inoculated with a series of pathogen races with known virulence and avirulence on individual resistance genes (24). Lines that are susceptible to one or more races of the pathogen are the most amenable to gene postulation. Gene postulation is the most widely used method to identify $L r$ genes, and several researchers have used this approach to identify $L r$ genes in various populations of wheat lines. Statler (42) postulated $L r l, 2 a, 2 c$, 10, 17, and 18 among 25 hard red spring wheats. Modawi et al. (27) identified Lr3a, 9,10 , and 24 among 30 winter wheat culti- vars. McVey (25) postulated $L r 1,3,10,16$, 24 , and 26 among 86 winter wheat cultivars obtained from international winter wheat nurseries from 26 countries. McVey and Long (26) postulated $L r l, 2 a, 3,3 k a$, $9,10,11,14 a, 16,17,18,24,26$, and 30 among 86 hard red winter wheat lines. Singh (38) identified $L r 1,3,13,16,17,23$, 26 , and 34 among 26 Mexican wheat cultivars. Singh and Rajaram (40) postulated Lr1, 3, 3bg, 10, 13, 14a, 16, 17, 19, 23, 26, and $27+31$ among 50 Mexican cultivars. Singh et al. (39) postulated $\operatorname{Lrl}, 3,3 \mathrm{bg}, 10$, $13,14 a, 16,23$, and 26 among 61 spring and 102 facultative and winter wheat cultivars from China. Singh et al. (37) postulated $L r 1,3 a, 10,13,17 b, 20,26$, and 37 among 70 cultivars from the United Kingdom. Gene Lr26 has been associated with wheat lines that have the 1BL.1RS translocation from rye (43).

Of 125 soft red winter wheat cultivars summarized by Roelfs et al. (31), 111 were considered old and the remaining 14 that overlapped in this study were considered contemporary. Genes $L r 1,2 a, 3,9,10,11$, $13,18,24,26,3 b g, 14 a, 14 b, 16,19,20$, and 31 were postulated in the old soft red winter wheat, of which the last seven were present in less than $2 \%$ of the cultivars.

The expression of some $L r$ genes is dependent on postinoculation temperatures. Browder (1) classified genes Lrl1, 14a, and 18 as highly sensitive and $L r 3 k a$ as moderately sensitive to temperature. Dyck and Johnson (4) reported better expression of $L r 11,14 a$, and 18 at temperatures below $20^{\circ} \mathrm{C}$; expression of $L r 3 \mathrm{ka}$ varied among races but not with temperature. Genes $L r 11$ and 18 were most effective at 14 to $18^{\circ} \mathrm{C}$ in greenhouse studies (40), and Park et al. (28) detected $\operatorname{Lr} 18$ at 18 to $20^{\circ} \mathrm{C}$.

Expression of some $L r$ genes has been shown to differ depending on whether the pathogen isolate was homozygous or heterozygous for avirulence. Kolmer and Dyck (15) reported that avirulence for genes $L r 2 a, 2 c, 3 k a, 11$, and 30 was partially (incompletely) dominant because isolates of $P$. triticina that were heterozygous for avirulence produced higher infection types than isolates that were homozygous for avirulence when tested on homozygous resistant wheat lines. Heterozygosity for avirulence to $L r$ genes appears to be common among field collections of $P$. triticina. Samborski and Dyck (34) found that among four races $(1,9,15$, 161 ), only race 9 was homozygous at all loci tested. Races 1, 15, and 161 segregated at a number of loci for avirulence when these races were selfed. Likewise, 
with the $P$. triticina population in eastern Canada, frequencies of virulence to $L r 3 \mathrm{ka}$, 11,17 , and 30 increased in aecial populations compared with uredial populations, indicating heterozygosity for avirulence (11).
Resistance to leaf rust in hard red winter wheat lines at the seedling stage is likely due to some combinations of race-specific seedling genes, probably $L r l, 3,3 k a, 9,10$, $11,14 a, 16,17,18,24,26$, and 30 $(12,25,26)$. However, less work has been done on the genetic basis for leaf rust resistance in winter wheat than in spring wheat (12). Lack of information on the genetic basis for resistance leads to uncertainty about durability of resistance and makes pyramiding resistance genes more

Table 1. Entries and pedigrees for the 1998-99 Arkansas Cultivar Performance Test and Uniform Southern and Eastern soft red winter wheat nursery

\begin{tabular}{|c|c|c|c|}
\hline Entry & Pedigree & Entry & Pedigree \\
\hline Agripro Foster & KY 83-60/Tyler//KY 83-75 & NC95-25305 & $\mathrm{C} 39 / 3 / \mathrm{FL} 302 / \mathrm{C} 8320 / / \mathrm{Cc}(\mathrm{Pm} 1)$ \\
\hline Agripro Hickory & Hunter/Caldwell & NC95-25707 & C8629/3/KS8338422//Stella/Caldwell \\
\hline Agripro Mallard & Wheeler/Caldwell & NK Coker 9025 & AL850046/Coker 86-23 \\
\hline Agripro Marion & VA82-52-64/AP-SW85-50009 & NK Coker 9152 & Coker 86-27/Coker 9733//Pioneer 2555 \\
\hline Agripro Mason & Cardinal//MN74143/Oligoculm/3/Coker 9232 & NK Coker 9184 & Coker $9803 /$ Coker 9835 \\
\hline Agripro Patton & SW85*94/IN82104B1-3-2 & NK Coker 9543 & Coker 916//Oasis/Coker 762 \\
\hline Agripro Shelby & $\begin{array}{l}\text { FL302/7/C81132/5/SO.Belle/4/Riley/Stoddart// } \\
\text { Top/3/Arthur/6/Coker } 983\end{array}$ & $\begin{array}{l}\text { NK Coker } 9663 \\
\text { NK Coker } 9704\end{array}$ & $\begin{array}{l}\text { IN71761A4-31-5-48/FL } 302 \\
\text { Coker 9803/Coker 983 }\end{array}$ \\
\hline Agripro Shiloh & Coker 833/Becker & NK Coker 9835 & Coker 85-20/Pioneer 2550 \\
\hline AGS2000 & Pioneer 2551/PF84301//FL302 & OH 536 & P71761A4-31-5-33/MD55-286-21 \\
\hline AP-D94-5282 & AP-E86-5258/AP-SW85-5009 & OH 552 & P71761A4-31-5-33/MD55-286-21 \\
\hline APD95*8811-1 & Coker 9835/APE87-1785 & OH599 & PS-840026/OH416 \\
\hline APD95*8811-2 & Coker 9835/APE87-1785 & OK91P648-41 & $2555 \mathrm{sib} / \mathrm{Vona} / / 2180$ \\
\hline APD95-7763 & Wakefield/Coker 9877 & P86364RA1-4-2-7 & INW9241//Clark/IL79-1458 \\
\hline Armor 3235 & Pioneer 2550/Keiser & P88204RB1-2-1-6 & P86982C2/P844030H1//P831800A1/Grant \\
\hline AR 584A-3-1 & Fl 302//Coker 833/Hunter & Pioneer 2548 & Hadden*2/3/GA1123//N10-B/Tenmarq/4/ \\
\hline BL931167 & Pioneer Exp.9021/FL791G63 & & MoW6582/Redcoat/5/Coker 68-15/4/Etiole de \\
\hline BL940026 & Coker 762//Coker 75-30//Coker 80-28 & & Chotsy//Thorne/Clarkan/3/Pawnee/IN3848A5 \\
\hline Buckshot's DS9193 & Not available & Pioneer 2684 & PL W9057B/Caldwell//Hunter \\
\hline Caldwell & Benhur sib*2/Siete Cerros & Pioneer 26R24 & Aurora/Tyler//2553/2550 sib/3/Cok 983/4/Cok 87-13 \\
\hline Cardinal & Logan*2/3/VA63-5-12/Logan//Blueboy & Pioneer 26R46 & FL7927-G14//2555*3.Coker 80-28 \\
\hline Delta Grow 3300 & Not available & Pioneer 26R61 & Omega 78/Pio S76/4/Arthur71/3/stadler//Redcoat/ \\
\hline Delta King $1551 \mathrm{~W}$ & Not available & & Wsc. $1 / 5 /$ Coker 747/6/2555sib \\
\hline Delta King 9027 & Not available & Pioneer XW672 & 2548/3/2555*3//2555 sib/KU81H1640/5/McN1003/ \\
\hline Delta King 9051 & Not available & & Caldwell/4/ IN4946A4/MoW7510//Cok71/3/2550 sib \\
\hline Delta King 9121 & Not available & Pocahontas & Wheeler*2/C39//Saluda \\
\hline Dixie 2000 & Not available & Quantum 708 & Not available \\
\hline Dixie 911 & Not available & Roane & VA71-54-147/Coker 68-15//IN65309C7-18-2-3-2 \\
\hline EK 103 & Not Available & Roberts & Coker $86-3 /$ Gore \\
\hline EK 156 & Not available & Sabbe & Corin/3/FL302//Coker 833/Hunter \\
\hline EK 114 & Not available & SS36803 & $831127-3 / / 821264 * 3 / 79102$ \\
\hline $\mathrm{F} 322 \mathrm{~W}$ & Not available & S9412192 & FL7925-G47-J10/FL8062-E4-H7-J1 \\
\hline FFR $522 \mathrm{~W}$ & P71761/Coker 797 & SC921285 & SL4/67-78/7/Tift72-60/Arthur 71//Gabota/3/ \\
\hline FFR $558 \mathrm{~W}$ & Not available & & LourinLL/4/ Tift72-60/Arthur 71/5/Beau/6/C76- \\
\hline FL8868 & FL302-H9 backcross line/GA781176 & & 22/8/Brule \\
\hline Florida 302 & $\begin{array}{l}(\mathrm{McN} 1003 / \mathrm{Ck} 762) \\
\text { Coker 65-20//P4946A4-18-2-10-1/Hadden/3/ } \\
\text { Vogel/5/ Anderson//P4946A4-18-2-10-1/Hadden }\end{array}$ & SC921299 & $\begin{array}{l}\text { SL4/67-78/7/Tift72-60/Arthur 71//Gabota/3/ } \\
\text { LourinLL/4/ Tift72-60/Arthur 71/5/Beau/6/C76- } \\
\text { 22/8/Brule }\end{array}$ \\
\hline G41332 & IL84-3010/T812 & SS550 & Coker 9803/Freedom \\
\hline G41333 & IL84-3010/T812 & Stine 455 & Not available \\
\hline G60232 & IL84-3511/T812 & Stine 488 & Not available \\
\hline GA881404E56 & C983/4/Aepoglom//C762/FL302/3/C762 & Stine 950455 & Not available \\
\hline GA88622E51 & Gore//831466/GA100 & T104 & $\mathrm{T} 814 * 2 / \mathrm{T} 408$ \\
\hline GA90524E35 & Coker 9835//FL302/Gore & T105 & $\mathrm{T} 814 * 2 / \mathrm{T} 408$ \\
\hline HT98-10033 & Feland/Becker//Chay/Stella & T106 & $\mathrm{T} 814 * 2 / \mathrm{T} 408$ \\
\hline HT98-10291 & Tyler*2/C65-20/Atr & T109 & T85/T814 \\
\hline IL91-15911 & IL84-3511/Caldwell & Terra E218 & Not available \\
\hline IL94-2894 & IL85-3132-1 (McN1003/Caldwell)/PSRW 71 & Terra SR 204 & Not available \\
\hline IL94-6727 & $\begin{array}{l}\text { IL87-3721 (Cardinal/Howell)/2*IL85-3132-1 } \\
\text { (McN1003/Caldwell) }\end{array}$ & $\begin{array}{l}\text { Terra SR216 } \\
\text { Terral TV } 8555\end{array}$ & $\begin{array}{l}\text { Not available } \\
\text { Not available }\end{array}$ \\
\hline Jackson & Saluda/Coker 762 & Terral TV 8768 & Not available \\
\hline Jaypee & Arthur 6/AR 39-3(Doublecrop//Forlani/Garibaldo) & Terral TV8825 & Not available \\
\hline KY86C-127-3 & $\begin{array}{l}\text { NA-SW76-59/NA-SW78-111 = composite } \\
\text { cross//Knox 62/SRW 14-74 }\end{array}$ & $\begin{array}{l}\text { Terral TVX8670 } \\
\text { TW94315 }\end{array}$ & $\begin{array}{l}\text { Not available } \\
\text { Casey/Century }\end{array}$ \\
\hline LA 87167D8-10-2 & GA8787:FR81-19/FL302//Coker 983 & TX87-20 & Caldwell/Sioux land \\
\hline LA8513B1-7-B-1-4-2 & FL302/Coker 762 & TX91-13 & FL8172-G98-L5/Gore \\
\hline LA90144B16-3-2 & Pioneer 2548/Coker 9835 & USG 3209 & Saluda/4/Massey*2/2/Massey*3/BALKAN//Saluda \\
\hline LA90412F14-1-4 & $\begin{array}{l}. . \mathrm{ms} / 3 / \mathrm{Ck} 983 / 4 / . . \mathrm{ms} / 3 / \mathrm{N} 76-261 / 5 / \mathrm{SC} 810779 / 6 / \\
\text { OP-ms/7/ Coker 797/8/Coker 9835 }\end{array}$ & $\begin{array}{l}\text { USG } 3408 \\
\text { USG Exp } 97-4\end{array}$ & $\begin{array}{l}\text { Not available } \\
\text { Not available }\end{array}$ \\
\hline LA9070G45-3-3-1 & Savannah/CEP75203//FL85363-G21-6 & VA96-54-326 & SC861562/Coker 9803 \\
\hline M95*2883 & Magnum/P101//OH394 & VA97W-375 & Coker 9803/Freedom \\
\hline M95*3330 & Roland/R269-74//HE270-15/3/Howell & Wakefield & Composite of Arthur//Doublecrop//Abe/VA68-24- \\
\hline M95*3349 & S76/N80738//Pioneer 2555 & & 42/3/,and Oasis/VA68-24-42//BYC113836/8* \\
\hline Madison & Abe//Blueboy/VA 71-54-147/3/VA 72-54-14 & & Chancellor F3 Derivatives \\
\hline MO94-317 & AP Traveller/Pioneer 2555 & Wilfarm 488 & Not available \\
\hline NC94-7197 & $\begin{array}{l}\text { Coker 83-23/Bradford//CC(PM1)/3/Coker } \\
\text { 8320/4/SXL/C39 }\end{array}$ & & \\
\hline
\end{tabular}


difficult. The objective of this study was to determine the genetic basis for racespecific resistance to leaf rust among 116 contemporary cultivars and advanced breeding lines of soft red winter wheat.

\section{MATERIALS AND METHODS}

The 116 lines from the 1998-99 Arkansas Wheat Cultivar Performance Test and Uniform Eastern and Southern Soft Red Winter Wheat Nurseries were selected as representative of contemporary soft red winter wheat cultivars and breeding lines at the beginning of this study (Table 1). Twenty-two races of $P$. triticina (Table 2) were selected to identify $L r$ genes in the lines. Isolates of $P$. triticina were obtained from the USDA-ARS, Cereal Disease Laboratory, St. Paul, MN, the Cereal Research Centre Agriculture and Agri-Food in Winnipeg, Canada, and from field collections in Arkansas.

To assure that each pathogen isolate was homogeneous, all isolates used in this study originated from a single-pustule transfer. To produce ample quantities of urediospores, each isolate was increased on wheat seedlings. Approximately 15 wheat seedlings were grown in $8.5-\mathrm{cm}$ square pots filled with potting mix (6 parts peat moss, 4 parts vermiculite, 2 parts perlite, 3 parts Roxanna silt loam, and 3 parts sand). Seedlings were fertilized at emergence and before inoculation with Peters 20-20-20 NPK fertilizer at the rate of $1 \mathrm{~g} /$ liter. To enhance spore production (20) and to prevent further leaf formation
(13), seedlings were treated with $20 \mathrm{ml}$ of $0.1 \%$ maleic hydrazide per pot when they were approximately $8 \mathrm{~cm}$ tall. When primary leaves were fully expanded, seedlings were inoculated with urediospores suspended in Soltrol 170 mineral oil (Chevron-Phillips Chemical Co., Houston, TX). Inoculated seedlings were placed in a dew chamber for 16 to $20 \mathrm{~h}$ at $20^{\circ} \mathrm{C}$ and then transferred to a greenhouse at 20 to $24^{\circ} \mathrm{C}$ or a growth chamber at $22 / 18^{\circ} \mathrm{C}$ (day/night) with a 12 -h photoperiod. Seedlings inoculated with each isolate were maintained in a separate, clean isolation chamber to avoid cross contamination. Urediospores were collected with a vacuum spore collector, dried in a desiccator, and kept at $5^{\circ} \mathrm{C}$ for short-term storage or at $-80^{\circ} \mathrm{C}$ for long-term storage.

To determine the avirulence/virulence formula, each isolate was inoculated on a set of 24 isolines in a Thatcher (Tc) background. Procedures were as described above except that isolines were not treated with maleic hydrazide and inoculated seedlings were incubated in a growth chamber at $22 / 18^{\circ} \mathrm{C}$ with a 12 -h photoperiod. Isolines were grouped into sets (set 1: TcLrl, $2 a, 2 c, 3$; set 2 : $T c L r 9,16,24,26$; set 3: TcLr3ka, 11, 17, 30; set 4: TcLr10, 18, 14a, 23; set 5: TcLr15, 20, 21, 28; and set 6: TcLr32, 36, 38, 39), and reactions on the first four sets were used to determine the race designation for each isolate as described by Long and Kolmer (17). Host response was measured by recording the infection type on the first leaf. Infection types were rated according to the 0 to 4 scale of Stakman et al. (41), where $0=$ no macroscopic symptoms, ; = hypersensitive necrotic or chlorotic flecks, $1=$ small uredia surrounded by necrosis, $2=$ medium uredia surrounded by necrosis or chlorosis, $3=$ medium uredia without necrosis or chlorosis, 4 = large uredia without necrosis or chlorosis, $+=$ uredia somewhat larger than normal for the infection type, and - = uredia somewhat smaller than normal. A range of infection type was recorded using more than one infection type with the predominant infection type listed first. Infection types 3 and 4 were considered high (host was susceptible/race was virulent), and others were considered low (host was resistant/race was avirulent). Each race by wheat isoline combination was tested at least twice.

To determine reactions of soft red winter wheat lines, five to seven seedlings from each of the 116 lines and 24 isolines were grown in $8.5-\mathrm{cm}$ square pots with four lines per pot. Wheat cultivars Morocco and Ernie were included in each test as susceptible controls. Plants were grown, inoculated, and incubated in a dew chamber as described previously. Inoculated plants were then incubated in growth chambers at $22 / 18^{\circ} \mathrm{C}$. Infection types were rated 12 to 14 days after inoculation. Each race by wheat line combination was tested at least twice.

To facilitate determining the absence or presence of $L r$ genes, infection type data were analyzed using a computer program

Table 2. Infection type ${ }^{\text {a }}$ produced by the 23 races of Puccinia triticina used in this study on seedlings of 24 Thatcher isolines with a single $L r$ gene at $22 / 18^{\circ} \mathrm{C}$ day/night and 12 -h photoperiod except as footnoted

\begin{tabular}{|c|c|c|c|c|c|c|c|c|c|c|c|}
\hline \multirow[b]{2}{*}{ Race } & \multirow[b]{2}{*}{ Isolate } & \multicolumn{10}{|c|}{$L r$ gene } \\
\hline & & 1 & $2 a$ & $2 c$ & 3 & 9 & 16 & 24 & 26 & $3 k a$ & 11 \\
\hline BBBB & - & ; & 1 & ; & $; 1$ & ; & ; & ; & ; & 1 & 1 \\
\hline CBGS & 85 CBG-677 & 0 & 0 & $; 1$ & & ; & 1 & $; 1$ & ; & 1 & \\
\hline CBTD & 89200 & ; & ; & $; 1$ & & ; & 1 & $; 1$ & ; & & \\
\hline DBBC & $1991 \mathrm{MI}$ & $; 1$ & $; 0$ & & ; & $; 1$ & 1 & 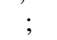 & $; 1$ & $11+$ & $2 ;^{\mathrm{b}}$ \\
\hline KBGQ & - & ; & & & & ; & 1 & ; & ; & 1 & \\
\hline LBBQ & 98FL119-1DLL & & 1 & ; & 12 & ; & 1 & $; 1$ & ; & $2+$ & $1^{\mathrm{b}}$ \\
\hline LBCS & - & & ; & $; 1$ & ; & $; 1$ & 1 & ; & $; 1$ & $; 1$ & $22+$ \\
\hline MBMN & W1935 & & ; & ; & & ; & 1 & ; & $; 1$ & & $2++^{b}$ \\
\hline MBRR & 243 AR & & ; & ; & & ; & 1 & ; & ; & & \\
\hline MCDN & $1998 \mathrm{MN}$ & & 2 & 2 & & ; & 1 & 1 & & 1 & $2+^{b}$ \\
\hline MCRN & $130 \mathrm{AR}$ & & ; & ; & & ; & 1 & ; & & & \\
\hline MFMP & $94 \mathrm{KS} 406$ & & ; & ; & & ; & 1 & & & & $2+^{\mathrm{b}}$ \\
\hline MGBN & $492-99$ & & 2 & $2+$ & & ; & & $; 1$ & $; 1$ & 2 & $2^{b}$ \\
\hline MGMN & $1994 \mathrm{MN}$ & & ; & 2 & & ; & & ; & ; & & $2^{b}$ \\
\hline PDLM & $27-2-2$ & & $; 2$ & & & 0 & $; 1$ & & ; & & $; 1^{\mathrm{b}}$ \\
\hline PNMT & 94 LA 1 & & ; & & & & 1 & & 1 & & $2++^{b}$ \\
\hline SBDB & 94 PA 82 & & & & ; & ; & 1 & ; & ; & ; & $2++^{b}$ \\
\hline TBPM & $19-3-2$ & & & & & 0 & $11+$ & ; & ; & & ; \\
\hline TCRN & $222 \mathrm{AR}$ & & & & & ; & 1 & 1 & & & \\
\hline TDRP & $486-99$ & & & & & ; & 1 & & 1 & & \\
\hline TFRP & 98 OK 235 & & & & & 0 & 1 & & & & \\
\hline TLGM & 99 AR M3 & & & & & & $11+$ & ; & ; & 1 & \\
\hline TLRT & 99 AR B1 & & & & & & 1 & $; 1$ & 1 & & \\
\hline
\end{tabular}

a $0=$ no macroscopic symptoms, ; = hypersensitive necrotic or chlorotic flecks, $1=$ small uredia surrounded by necrosis, $2=$ medium uredia surrounded by necrosis or chlorosis, $3=$ medium uredia without necrosis or chlorosis, $4=$ large uredia without necrosis or chlorosis, $+=$ uredia somewhat larger than normal, $-=$ uredia somewhat smaller than normal. A range of infection type is indicated by more than one infection type, with the predominant infection type listed first. Blanks represent high infection types.

b Tested at $17^{\circ} \mathrm{C}$ and a 12 -h photoperiod.

c Tested at $18^{\circ} \mathrm{C}$ and a 12 -h photoperiod. 
written specifically for this purpose (Y. A. Wamishe, K. C. Thompson, and E. A. Milus, unpublished). Based on the genefor-gene concept, lines susceptible to a particular race cannot have an $L r$ gene for which the race is avirulent. For each line, step 1 of the program summarized results from races that were virulent on the line to definitively exclude $L r$ genes from the line, and this exclusion resulted in a relatively short list of $L r$ genes that could be present in the line. Step 2 of the program utilized data from races that were avirulent on the line, and the output listed the low infection types produced on the line and the isolines with $L r$ genes that were not excluded in step 1. Of the $L r$ genes not excluded in step 1, a gene was considered present if the low infection type produced on the line by one or more races matched the low infection type on the corresponding isoline. Otherwise, the gene was considered possibly present. Epistatic effects prevented the definitive inclusion or exclusion of genes considered possibly present. If the low infection type produced on the line was lower than that on any of the isolines in step 2, then the line was considered to have an unidentified $L r$ gene; i.e., the gene was not in the set of 24 isolines.

To correctly determine the reaction of genes $\mathrm{Lrll}$ and 18 that are more effective at low temperature, races that appeared to be avirulent on $\operatorname{Lrll}$ or 18 at $22 / 18^{\circ} \mathrm{C}$ day/night in preliminary tests were retested twice on the isolines and wheat lines at 17 or $18^{\circ} \mathrm{C}$, respectively. Races TBPM and PDLM that were identified as homozygous avirulent for Lrll by Kolmer and Dyck (15) were obtained late in the study from J. Kolmer (USDA, ARS, Cereal Disease Laboratory, St. Paul, MN) and used to confirm the presence of $\operatorname{Lrll}$ at $17^{\circ} \mathrm{C}$. Infection types obtained from these tests were used to postulate genes $\operatorname{Lrll}$ and 18 .

To obtain an indication as to whether avirulence for an $L r$ gene was fully or partially dominant, the range of low (avirulent) infection types on each Thatcher isoline in this study was examined.

To confirm the absence of $L r$ genes in the lines postulated to have no resistance genes based on inoculations with 22 races, seedlings of these lines were inoculated with race BBBB that was avirulent on all 24 isolines. Two lines that had an intermediate infection type with race BBBB were suspected to have Lr14a. These lines and appropriate isolines were inoculated with races avirulent on $\operatorname{Lr} 14 a$ and incubated at $18^{\circ} \mathrm{C}$ with a $12-\mathrm{h}$ photoperiod to determine if these lines had Lr14a.

To determine if Lr26 was always associated with 1BL.1RS status and vice versa, the presence of $L r 26$ as determined by postulation was compared to 1BL.1RS status (8).

\section{RESULTS}

The low infection types produced by races on the isolines with $\mathrm{Lr}$ genes (Table 2) agreed with low infection types for these genes as summarized by McIntosh et al. (24). Therefore, data obtained for lines (Table 3) can be used to accurately determine the presence or absence of these $L r$ genes in soft red winter wheat lines. Races differed for combinations of virulence on genes $L r 1,2 a, 2 c, 3,3 k a, 9,10,11,14 a$, $15,16,17,18,20,23,24,26,28$, and 30 , making it possible to postulate these genes. All races were avirulent on $\operatorname{Lr} 21,32,36$, 38 , and 39 , and these genes were not detected in any of the lines.

Of the 116 lines tested, 13 lines had no detectable seedling $L r$ genes, 49 had one or more known $L r$ genes, 35 had one or more known $L r$ genes and one or more unidentified $L r$ genes, and 19 had one or more unidentified $\mathrm{Lr}$ genes (Table 4). Considering the $L r$ genes postulated to be present (excluding the unidentified genes), 44 different combinations of $L r$ genes were identified among the 116 lines.

Four lines (Agripro Marion, APD945282, NC94-7197, and VA97W-375) were resistant to all races used in this study. The low infection types produced on these lines with races avirulent on $\operatorname{Lr} 26$ matched for $\operatorname{Lr} 9,24$, and 26. Races MFMP and TFRP that were virulent on both $L r 24$ and 26 indicated the presence of $L r 9$, and race TLGM that was virulent on both $\operatorname{Lr} 9$ and 26 indicated the presence of Lr24. Race PNMT that was virulent on both $L r 9$ and 24 displayed low infection type that matched for $L r 26$. These lines were postulated to have a combination of $\operatorname{Lr} 9,24$, and 26 by matching infection types and using the 1BL.1RS translocation as a marker for $\operatorname{Lr} 26$. The combination of $\operatorname{Lr} 9,24$, and 26 was epistatic over all other $L r$ genes, and therefore, none of the other $L r$ genes could be eliminated. For clarity, however, these

Table 2. (continued)

\begin{tabular}{|c|c|c|c|c|c|c|c|c|c|c|c|c|c|}
\hline \multicolumn{14}{|c|}{$L r$ gene } \\
\hline 17 & 30 & 10 & 18 & $14 a$ & 23 & 15 & 20 & 21 & 28 & 32 & 36 & 38 & 39 \\
\hline 1 & $; 1$ & 1 & 1 & $22+^{\mathrm{c}}$ & $; 1$ & 1 & $2+$ & 1 & ;2 & 1 & 1 & ; & 1 \\
\hline ; & 1 & & & & $2+$ & & & 2 & & 1 & 1 & ; & ; \\
\hline & & ; & $2+^{c}$ & & 1 & & & 1 & & 1 & 2 & ; & $; 1$ \\
\hline $1+$ & 1 & 1 & $2+^{c}$ & $2+^{\mathrm{c}}$ & & $2+$ & $2+$ & 2 & $2+$ & $; 1$ & $; 1$ & ; & $; 1$ \\
\hline ; & 1 & & & & $2+$ & & & 2 & & ; & ; & ; & ; \\
\hline 1 & 1 & & & $22+^{\mathrm{c}}$ & 1 & 2 & 2 & 1 & & ; & 1 & ; & 1 \\
\hline$; 1$ & & & & & $22+$ & & & 12 & & $; 1$ & $; 1$ & ; & $; 1$ \\
\hline 1 & & & $21^{\mathrm{c}}$ & & 1 & & & ; & & $; 1$ & $; 1$ & $; 1$ & 2 \\
\hline 1 & & & & $2+^{c}$ & & 2 & $2+$ & 1 & $2+$ & ;1 & 1 & ; & $; 1$ \\
\hline & 1 & & $2^{\mathrm{c}}$ & & 1 & & $; 1$ & 1 & & 2 & 1 & ; & $1 ;$ \\
\hline 1 & & & $2^{\mathrm{c}}$ & & 1 & & ;2 & 1 & & ;1 & $1 ;$ & ; & 1 \\
\hline 1 & & & $2^{c}$ & & & & & 1 & & 1 & 1 & ; & $; 1$ \\
\hline 1 & 1 & & $2+^{\mathrm{c}}$ & & 1 & 2 & 2 & ; & & $; 1$ & 1 & ; & 1 \\
\hline 2 & & & $2^{c}$ & & 1 & 1 & ; & $1+$ & $2+$ & 1 & 1 & ; & ; \\
\hline ; & $1+$ & & $2^{\mathrm{b}}$ & $22+^{c}$ & & & & 1 & & $; 1$ & $1+;$ & ; & ; \\
\hline ; & & & & & & & & ; & & 1 & 1 & ; & 2 \\
\hline & ; & ; & $1^{\mathrm{c}}$ & $2+^{c}$ & ; & $2+$ & ; & 1 & $2+$ & 12 & 1 & ; & 1 \\
\hline & & & $; 1^{\mathrm{b}}$ & $22+^{\mathrm{c}}$ & & & & ;1 & & $; 1$ & 2 & 0 & $; 1$ \\
\hline ; & & & $2^{c}$ & & 1 & 2 & ; & 1 & & 1 & 1 & $; 0$ & 1 \\
\hline ; & & & $2+^{\mathrm{c}}$ & & & & & 2 & & 1 & 1 & ; & 1 \\
\hline 1 & & & $2+^{\mathrm{c}}$ & & & & & 1 & & ;1 & $; 1$ & ; & ; \\
\hline 1 & 2 & & $2^{\mathrm{c}}$ & $2+^{c}$ & & & $2+$ & 1 & $2+$ & 2 & 1 & ; & $; 1$ \\
\hline ; & & & & & & & & 1 & & 1 & $; 1$ & 0 & $; 1$ \\
\hline
\end{tabular}


Table 3. Infection types produced by 23 races of Puccinia triticina on 116 soft red winter wheat lines

\begin{tabular}{|c|c|c|c|c|c|c|c|c|c|c|}
\hline \multirow[b]{2}{*}{ Line } & \multicolumn{10}{|c|}{ Race } \\
\hline & ВBBB & CBGS & CBTD & DBBC & KBGS & LBBQ & LBCS & MBMN & MBRR & MCDN \\
\hline Agripro Foster & $\mathrm{NT}^{\mathrm{a}}$ & 0 & ; & ; & ; & ; & ; & 1 & 1 & 1 \\
\hline Agripro Hickory & NT & 3 & 3 & ; & 3 & $3-$ & 3 & $; 1$ & 4 & ; \\
\hline Agripro Mallard & NT & 3 & 3 & 3 & 3 & 3 & 3 & 3 & 3 & 3 \\
\hline Agripro Marion & NT & ; & ; & ; & ; & ; & $-^{c}$ & ; & 1 & 1 \\
\hline Agripro Mason & NT & ; & ; & ; & ; & ; & ; & ; & ; & $; 1$ \\
\hline Agripro Patton & NT & 0 & ; & ; & ; & ; & 1 & ; & ; & 1 \\
\hline Agripro Shelby & NT & 3 & ; & 1 & 3 & 4 & $1 ;$ & 3 & 3 & 3 \\
\hline Agripro Shiloh & NT & 0 & ; & ; & ; & 1 & 1 & ; & ; & ; \\
\hline AGS 2000 & NT & ; & ; & ; & ; & ; & ; & 1 & 1 & 1 \\
\hline APD94-5282 & NT & ; & ; & ; & ; & ; & ; & ; & 1 & 1 \\
\hline APD95*8811-1 & NT & 0 & ; & ; & ; & ; & ; & ; & ; & ; \\
\hline APD95*8811-2 & NT & ; & ; & ; & ; & ; & ; & ; & ; & ; \\
\hline APD95-7763 & NT & ; & ; & ; & ; & ; & ; & ; & ; & ; \\
\hline AR584A-3-1 & NT & 3 & ; & ; & ; & 3 & $; 1^{\mathrm{b}}$ & 3 & 3 & $2+{ }^{b}$ \\
\hline Armor 3235 & NT & ; & ; & ; & $2+$ & 3 & 3 & 3 & 3 & 3 \\
\hline BL931167 & NT & ; & ; & ; & ; & ; & ; & ; & ; & 1 \\
\hline BL940026 & NT & ; & ; & ; & ; & ; & ; & ; & ; & ; \\
\hline Buckshot's DS9193 & NT & ; & ; & ; & ; & ; & ; & ; & ; & 1 \\
\hline Caldwell & 3 & 3 & 3 & 3 & 3 & 3 & 4 & 3 & 3 & 3 \\
\hline Cardinal & NT & 3 & 1 & 1 & 3 & 3 & 1 & 3 & 3 & $1^{\mathrm{b}}$ \\
\hline Delta Grow 3300 & NT & 3 & 3 & 3 & 3 & 3 & 3 & 3 & 3 & 3 \\
\hline Delta King 1551W & NT & 3 & $2+$ & 1 & 3 & $2+$ & $; 1$ & $0 ; \mathrm{b}$ & 3 & $22+$ \\
\hline Delta King 9027 & NT & 3 & $2++^{b}$ & $1^{\mathrm{b}}$ & 3 & 3 & 3 & 3 & 3 & 3 \\
\hline Delta King 9051 & NT & 3 & $2++^{\mathrm{b}}$ & 3 & 3 & 3 & 4 & 3 & $1^{\mathrm{b}}$ & $2^{\mathrm{b}}$ \\
\hline Delta King 9121 & NT & $;^{\mathrm{b}}$ & 3 & 3 & 3 & 4 & 4 & 3 & 3 & 3 \\
\hline Dixie 2000 & NT & ; & ; & ; & ; & ; & ; & ; & ; & ; \\
\hline Dixie 911 & $22+$ & 3 & 3 & $2+$ & 3 & 3 & 4 & 3 & 4 & 3 \\
\hline EK103 & NT & 3 & 3 & 3 & 3 & 3 & $;^{\mathrm{b}}$ & 3 & 4 & 3 \\
\hline EK114 & NT & 3 & 3 & $; 1$ & 3 & $3-;$ & 1 & $0 ;{ }^{\mathrm{b}}$ & 3 & $2+$ \\
\hline EK156 & NT & 3 & 3 & 3 & 3 & 3 & $; 0^{\mathrm{b}}$ & 3 & 3 & 3 \\
\hline F322W & NT & 3 & 3 & 3 & 3 & 4 & $; 1^{\mathrm{b}}$ & 3 & 3 & 3 \\
\hline FFR 522W & NT & ; & ; & ; & ; & ; & ; & ; & ; & ; \\
\hline FFR 558W & NT & ; & ; & ; & ; & ; & ; & ;1 & 1 & 1 \\
\hline Florida 302 & NT & 3 & ; & ; & 3 & 3 & 2 & 3 & 3 & 3 \\
\hline Florida 8868 & NT & ; & ; & ; & ; & ; & ; & ; & ; & ; \\
\hline G41332 & 3 & 3 & 3 & 3 & 3 & 4 & 4 & 3 & 3 & 4 \\
\hline G41333 & 3 & 3 & 3 & 3 & 3 & 4 & 3 & 3 & 3 & 4 \\
\hline G60232 & $1 ; \mathrm{b}$ & 3 & 3 & 3 & 3 & 3 & - & 3 & 3 & 3 \\
\hline GA881404E56 & NT & ; & ; & ; & 3 & ; & ; & ; & ; & ; \\
\hline GA88622E51 & NT & ; & ; & ; & ; & ; & $2+$ & ; & ; & ; \\
\hline GA90524E35 & NT & ; & ; & ; & ; & ; & ; & ; & ; & ; \\
\hline HT98-10033 & NT & ; & ; & ; & ; & 3 & $; 2+$ & 3 & 3 & 3 \\
\hline НТ98-10291 & NT & ; & ; & ; & ; & ; & ; & ; & ; & ; \\
\hline IL91-15911 & 3 & 3 & 3 & 3 & 3 & 3 & 3 & 3 & 3 & 3 \\
\hline IL94-2894 & NT & ; & ; & ; & ; & 3 & $1^{\mathrm{b}}$ & 3 & 3 & 3 \\
\hline IL94-6727 & NT & 3 & 3 & 3 & 3 & 3 & $2+^{\mathrm{b}}$ & $1^{\mathrm{b}}$ & 3 & 4 \\
\hline Jackson & NT & ; & ; & ; & ; & $2+$ & $; 1$ & $; 1^{\mathrm{b}}$ & 4 & $2+$ \\
\hline Jaypee & NT & $2+{ }^{b}$ & ; & ; & 3 & $2+$ & ; & $; 1^{\mathrm{b}}$ & 3 & $; 0^{\mathrm{b}}$ \\
\hline KY86C-127-3 & NT & ; & ; & ; & ; & ; & ; & 1 & ; & 1 \\
\hline LA 87167D8-10-2 & $\mathrm{NT}$ & $2^{b}$ & ; & ; & 3 & $3-$ & $; 1$ & $22+$ & 3 & 1 \\
\hline LA8513B1-7-B-1-4-2 & NT & ; & ; & ; & ; & ; & ; & ; & ; & ; \\
\hline LA90144B16-3-2 & $\mathrm{NT}$ & ; & ; & ; & ; & ; & ; & ; & ; & ; \\
\hline LA90412F14-1-4 & NT & ; & ; & ; & ; & ; & ; & ; & ; & ; \\
\hline LA9070G45-3-3-1 & NT & ; & ; & ; & ; & ; & ; & ; & ; & ; \\
\hline M95*2883 & NT & 3 & $2+$ & ; & 3 & $3-;$ & $2+$ & $1+^{\mathrm{b}}$ & 3 & $2+$ \\
\hline M95*3330 & NT & 3 & $2++^{b}$ & $1+^{\mathrm{b}}$ & 3 & 3 & 3 & 3 & 3 & 3 \\
\hline M95*3349 & NT & 3 & $2+$ & ; & 3 & $3-$ & ;2 & 3 & 3 & 3 \\
\hline Madison & NT & 3 & ; & 1 & 3 & 2 & $; 1$ & $2+$ & 3 & $2+$ \\
\hline MO94-317 & $\mathrm{NT}$ & 3 & $2+$ & ; & 3 & 3 & $1^{\mathrm{b}}$ & 3 & 3 & 3 \\
\hline NC94-7197 & NT & ; & ; & ; & ; & ; & $2+$ & ; & 1 & ; \\
\hline NC95-25305 & $\mathrm{NT}$ & 3 & $1^{\mathrm{b}}$ & $2+$ & $; 1^{\mathrm{b}}$ & $2+$ & 3 & $1^{\mathrm{b}}$ & 2 & $; 1^{\mathrm{b}}$ \\
\hline NC95-25707 & NT & ; & ; & ; & ; & ; & ; & ; & ; & ; \\
\hline NK Coker 9025 & NT & 0 & ; & ; & 3 & ; & $; 1$ & 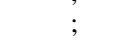 & 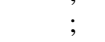 & $; 1$ \\
\hline NK Coker 9152 & NT & ; & 1 & ; & ; & ; & ; & ; & ; & ; \\
\hline NK Coker 9484 & NT & ; & ; & ; & 3 & ; & $; 1$ & ; & ; & 21 \\
\hline NK Coker 9543 & NT & 3 & $2+$ & 1 & 3 & $3-$ & 1 & $3-$ & 3 & $2+$ \\
\hline NK Coker 9663 & NT & ; & ; & ; & ; & ; & ; & ; & ; & ; \\
\hline NK Coker 9704 & NT & 3 & ; & 1 & 3 & 3 & 1 & 3 & 3 & 3 \\
\hline NK Coker 9835 & NT & ; & ; & ; & ; & ; & ; & ; & ; & ; \\
\hline
\end{tabular}

a Not tested.

${ }^{\mathrm{b}}$ A resistant reaction that could not be matched to any of the $L r$ genes in the set of isolines, indicating the presence of an unidentified gene.

c Missing data. 
Table 3. (continued)

\begin{tabular}{|c|c|c|c|c|c|c|c|c|c|c|c|c|}
\hline \multicolumn{13}{|c|}{ Race } \\
\hline MCRN & MFMP & MGMN & MGBN & PDLM & PNMT & SBDB & TBPM & TCRN & TDRP & TFRP & TLGM & TLRT \\
\hline 2 & 2 & ; & 1 & NT & 1 & 1 & NT & ; & 1 & 3 & ; & 1 \\
\hline $2+$ & 0 & ;1 & 12 & ; & $3-$ & 0 & ; & $2+$ & 3 & $2+$ & 3 & 3 \\
\hline 3 & $1^{\mathrm{b}}$ & 3 & 3 & 3 & 3 & 3 & 3 & 3 & 3 & 3 & 3 & 3 \\
\hline ;2 & ; & ; & ; & NT & ; & $; 1$ & NT & 1 & ; & ; & ; & ; \\
\hline ; & 0 & ; & ; & NT & 2 & ; & NT & ; & ; & 0 & 3 & 3 \\
\hline ;1 & 2 & ; & ; & NT & ; & 1 & NT & 1 & 1 & 3 & ; & ; \\
\hline 3 & 4 & 3 & 3 & 3 & 3 & ;1 & 3 & 3 & 4 & 3 & 4 & 3 \\
\hline ; & ; & ; & ; & NT & ; & ; & NT & ; & ; & 0 & 3 & 3 \\
\hline 2 & 2 & ; & ; & NT & 1 & ; & NT & 1 & 1 & 3 & ; & ; \\
\hline 1 & 1 & ; & $; 1$ & NT & 1 & 1 & NT & ; & 1 & 1 & ; & ; \\
\hline ; & ; & ; & ; & NT & 3 & ; & NT & ; & 2 & 0 & 4 & 3 \\
\hline ; & ; & ; & ; & NT & 1 & ; & NT & $;$ & 1 & ; & 2 & 3 \\
\hline ; & 0 & ; & ; & NT & 3 & ; & NT & $;$ & 0 & 0 & ; & 1 \\
\hline 3 & 3 & 3 & 3 & 3 & $2^{b}$ & ; & 3 & 3 & 3 & 4 & 4 & 3 \\
\hline 3 & 3 & 3 & 3 & NT & 4 & 3 & NT & 3 & 4 & 4 & 4 & 3 \\
\hline ; & ; & ; & ; & NT & 3 & ; & NT & ; & 2 & 0 & 3 & 3 \\
\hline ; & 0 & ; & ; & NT & 1 & 1 & NT & $;$ & 0 & 0 & 4 & 3 \\
\hline ; & 0 & ; & ; & NT & ; & ; & NT & ; & ; & 0 & 4 & 3 \\
\hline 3 & 3 & 3 & 3 & NT & 3 & 3 & NT & 3 & 4 & 3 & 4 & 3 \\
\hline 3 & 4 & 3 & 3 & NT & 3 & 1 & NT & 3 & 3 & 4 & 3 & 3 \\
\hline 3 & 3 & 3 & 3 & NT & 3 & 3 & NT & 4 & 4 & 4 & 4 & 3 \\
\hline 3 & 2 & 1 & 1 & $; 1$ & $1^{b}$ & $3-$ & ; & 4 & 4 & 3 & 4 & 3 \\
\hline 3 & 4 & 3 & 3 & 3 & 3 & $2^{\mathrm{b}}$ & 3 & 3 & 4 & 4 & 4 & 3 \\
\hline 3 & 3 & 3 & 3 & 3 & 3 & 3 & 3 & 3 & 4 & 3 & 3 & 3 \\
\hline 3 & $2^{\mathrm{b}}$ & 3 & 3 & $2^{b}$ & 3 & 3 & 3 & 3 & 3 & 3 & 3 & 3 \\
\hline ; & 2 & ; & ; & NT & $2+$ & ; & NT & ; & ; & 0 & $3-$ & 3 \\
\hline 3 & 3 & 3 & 3 & 3 & 3 & $2+$ & 3 & 3 & 4 & 4 & 3 & 3 \\
\hline 3 & 3 & $1^{b}$ & 3 & 3 & 3 & 3 & 3 & 3 & 3 & 3 & 4 & 3 \\
\hline 3 & $1^{\mathrm{b}}$ & 1 & $0 ; \mathrm{b}$ & ;1 & $1^{\mathrm{b}}$ & $3-$ & ; & 3 & 4 & 3 & 4 & 3 \\
\hline 3 & 3 & 3 & 3 & 3 & 3 & 3 & 3 & 3 & 4 & 4 & 4 & 3 \\
\hline 3 & 3 & 3 & 3 & 3 & 3 & 3 & 3 & 3 & 4 & 3 & 4 & 3 \\
\hline ; & ; & ; & ; & NT & $2+$ & ; & NT & ; & ; & 0 & $2+$ & 3 \\
\hline- & 3 & ; & ; & NT & 1 & 1 & NT & 1 & 1 & 3 & ; & 1 \\
\hline 3 & 3 & 3 & 3 & 3 & 3 & ; & 3 & 3 & 3 & 3 & 4 & 4 \\
\hline ; & 0 & ; & ; & NT & $2+$ & ; & NT & ; & 3 & $0^{\mathrm{b}}$ & 4 & 3 \\
\hline 3 & 3 & 3 & 3 & NT & 3 & 3 & NT & 3 & 3 & 3 & 4 & 3 \\
\hline 3 & 3 & 3 & 3 & NT & 3 & 3 & NT & 3 & 3 & 3 & 4 & 3 \\
\hline 3 & 3 & 3 & 3 & NT & 3 & 3 & NT & 3 & 4 & 3 & 4 & 3 \\
\hline ; & 0 & ; & 0 & ; & 1 & 0 & $2+$ & 3 & ; & 3 & 4 & 3 \\
\hline ; & 1 & 1 & $1 ;$ & NT & $2+$ & ; & NT & ; & 3 & 3 & ; & ; \\
\hline ; & 0 & ; & ; & NT & 1 & ; & NT & $;$ & ; & 0 & 4 & 3 \\
\hline 3 & 3 & 3 & 3 & NT & 3 & 2 & NT & 3 & 3 & 3 & 4 & 3 \\
\hline ; & 3 & ; & $2+$ & NT & 3 & ; & NT & ; & 4 & $1^{\mathrm{b}}$ & ; & 1 \\
\hline 3 & 4 & 3 & 3 & NT & 3 & 3 & NT & 3 & 4 & 4 & 4 & 3 \\
\hline 3 & 4 & 3 & 3 & NT & 3 & 3 & NT & 3 & 3 & 4 & 4 & 3 \\
\hline 3 & 3 & 3 & 3 & 3 & $3+$ & 3 & 3 & 3 & 3 & 3 & 4 & 3 \\
\hline 3 & $; 12^{\mathrm{b}}$ & $; 2+^{\mathrm{b}}$ & 12 & $; 1$ & $1^{\mathrm{b}}$ & ; & ; & 3 & 3 & 3 & 3 & 3 \\
\hline 3 & $; 1^{\mathrm{b}}$ & $11+$ & 1 & $; 1$ & $3-$ & ; & ; & 3 & 3 & 3 & $1^{\mathrm{b}}$ & $1^{\mathrm{b}}$ \\
\hline $2+$ & $2+$ & ; & 1 & NT & 1 & 1 & NT & $; 1$ & 1 & 3 & ; & ; \\
\hline 3 & 1 & 2 & ; & ; & $1^{\mathrm{b}}$ & ; & ; & $1 ; \mathrm{b}$ & $1^{\mathrm{b}}$ & $1^{\mathrm{b}}$ & $1^{\mathrm{b}}$ & $1^{\mathrm{b}}$ \\
\hline ; & 0 & ; & ; & NT & ;1 & ; & NT & ; & 0 & 0 & 4 & 3 \\
\hline ; & 0 & ; & ; & NT & ;1 & ; & NT & ; & 0 & 1 & $2+$ & 3 \\
\hline ; & 0 & ; & ; & NT & ; & ; & NT & ; & ; & ; & $2+$ & 3 \\
\hline ; & ; & ; & ; & NT & $2+$ & ; & NT & ; & ; & 0 & 4 & 3 \\
\hline 3 & $0^{\mathrm{b}}$ & - & $3-$ & $; 1$ & 2 & $2+$ & $; 1$ & 3 & 3 & 4 & 3 & 3 \\
\hline 3 & 3 & 3 & 3 & 3 & 3 & 3 & 3 & 3 & 3 & 3 & 4 & 3 \\
\hline 3 & 3 & 3 & 3 & NT & $3+$ & 1 & NT & 3 & 3 & 3 & 4 & 3 \\
\hline 3 & $j^{\mathrm{b}}$ & $; 2+\mathrm{b}$ & ; & $; 1$ & $2+$ & ; & ; & 3 & 3 & 3 & 3 & 3 \\
\hline 3 & 4 & 3 & 3 & NT & 3 & 1 & NT & 3 & 3 & 4 & 4 & 3 \\
\hline 1 & ; & ; & ; & NT & 1 & ; & NT & 1 & 1 & ; & ; & 0 \\
\hline 2 & $3-^{\mathrm{b}}$ & ; & ; & 3 & $1^{b}$ & ; & 3 & 1 & $1^{\mathrm{b}}$ & $1^{b}$ & 2 & $1^{\mathrm{b}}$ \\
\hline ; & ; & ; & ; & NT & $2+$ & ; & NT & ; & ; & ; & 4 & 3 \\
\hline ; & 0 & ; & ; & $2+$ & 1 & ; & 3 & 3 & 0 & 3 & 4 & 3 \\
\hline ; & $; 1$ & ; & 1 & 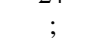 & 1 & ; & ; & ; & 3 & $; 1^{\mathrm{b}}$ & ; & ; \\
\hline ; & ; & ; & $2+$ & ; & ; & 1 & ; & 3 & $1^{\mathrm{b}}$ & 3 & 4 & ;b \\
\hline 3 & ; & 1 & $1+$ & $; 1$ & 1 & 2 & ;1 & 3 & 4 & 1 & 3 & 3 \\
\hline ; & ; & ; & ; & NT & $2+$ & ; & NT & ; & ; & 0 & 4 & 3 \\
\hline 3 & 3 & 3 & 3 & NT & 3 & ; & NT & 3 & 3 & 3 & 3 & 3 \\
\hline ; & 0 & ; & ; & NT & ; & ; & NT & ; & ; & 0 & $2+$ & 3 \\
\hline
\end{tabular}


Table 3. (continued from previous spread)

\begin{tabular}{|c|c|c|c|c|c|c|c|c|c|c|}
\hline \multirow[b]{2}{*}{ Line } & \multicolumn{10}{|c|}{ Race } \\
\hline & BBBB & CBGS & CBTD & DBBC & KBGS & LBBQ & LBCS & MBMN & MBRR & MCDN \\
\hline OH536 & NT & 3 & 2 & ; & 3 & 3 & $2+$ & 3 & $1^{\mathrm{b}}$ & $2 ; \mathrm{b}$ \\
\hline OH552 & NT & 3 & $2+$ & 1 & 3 & 2 & $2+$ & 3 & 3 & 3 \\
\hline OH599 & NT & 3 & 1 & ; & 3 & 0 & 1 & $0^{\mathrm{b}}$ & 3 & $;^{\mathrm{b}}$ \\
\hline OK91P648-41 & NT & 3 & $2^{\mathrm{b}}$ & $1^{\mathrm{b}}$ & $;^{\mathrm{b}}$ & 3 & $1^{\mathrm{b}}$ & 3 & 3 & 3 \\
\hline P86364RA1-4-2-7 & NT & ; & ; & ; & $2+$ & ; & $; 1$ & 1 & 3 & $1 ;$ \\
\hline P88204RB1-2-1-6 & NT & 2 & 3 & 3 & 3 & 3 & $; 2+b$ & 3 & 3 & 3 \\
\hline P92227C5-1-1 & NT & 1 & $j^{b}$ & ; b & 3 & 3 & $1^{\mathrm{b}}$ & 3 & 3 & 3 \\
\hline Pioneer 2548 & NT & 3 & $2+$ & 1 & 3 & $3-$ & 1 & $0 ; \mathrm{b}$ & 3 & $2+$ \\
\hline Pioneer 2684 & NT & 3 & 1 & ; & $; \mathrm{b}$ & $3-$ & $; 1$ & ; & 3 & 1 \\
\hline Pioneer 26R46 & NT & ; & ; & ; & ; & $3-$ & ; & ; & 3 & $2+$ \\
\hline Pioneer 26R61 & NT & ; & ; & ; & ; & ; & ; & ; & 1 & 2 \\
\hline Pioneer XW672 & NT & $2+$ & $2+$ & 1 & 1 & $; 1$ & $; 1$ & $; 1^{\mathrm{b}}$ & $1^{\mathrm{b}}$ & $3-$ \\
\hline Pioneer 26R24 & $1 ; \mathrm{b}$ & 3 & 3 & 3 & 3 & 3 & 4 & 3 & 3 & 3 \\
\hline Pocahontas & NT & 3 & 3 & 2 & 3 & $; 1$ & 1 & ;b & 3 & $2+$ \\
\hline Quantum 708 & NT & ; & ; & ; & ; & ; & ; & $; 1$ & $; 1$ & 1 \\
\hline Roane & NT & 3 & 3 & 3 & 3 & 4 & 3 & 3 & 4 & 3 \\
\hline Roberts & NT & 3 & 3 & $; 1$ & 3 & $3-$ & $2+$ & $;^{b}$ & 3 & $0 ; \mathrm{b}$ \\
\hline S9412192 & NT & ; & ; & ; & ; & ; & $3-$ & 1 & ; & ; \\
\hline Sabbe & NT & ; & ; & ; & ; & $; 1$ & $; 2$ & ; & ; & 1 \\
\hline SC921285 & NT & $1^{\mathrm{b}}$ & 3 & 3 & 3 & 3 & ${ }^{\mathrm{b}}$ & $1^{\mathrm{b}}$ & $1^{\mathrm{b}}$ & $2^{\mathrm{b}}$ \\
\hline SC921299 & NT & $2^{\mathrm{b}}$ & $2^{\mathrm{b}}$ & $2^{\mathrm{b}}$ & 3 & $2^{b}$ & 4 & $1^{\mathrm{b}}$ & 3 & 3 \\
\hline SS36803 & NT & 3 & $2+$ & $1+$ & 3 & $2+$ & ; & ; b & 3 & $; 1^{\mathrm{b}}$ \\
\hline SS550 & NT & ; & ; & ; & ; & ; & ; & ; & 1 & 1 \\
\hline Stine 455 & $2+$ & 3 & 3 & $2+$ & 3 & 3 & 4 & 3 & 3 & 3 \\
\hline Stine 488 & 3 & 3 & 3 & 3 & 3 & 3 & 4 & 3 & 4 & 3 \\
\hline Stine 950455 & NT & 3 & 1 & 1 & 3 & $3-$ & $; 1$ & $2+$ & 3 & $2+$ \\
\hline T104 & 3 & 3 & 3 & 3 & 3 & 3 & 4 & 3 & 3 & 4 \\
\hline T105 & 3 & 3 & 3 & 3 & 3 & 4 & 4 & 3 & 3 & 4 \\
\hline T106 & 3 & 3 & 3 & 3 & 3 & 3 & 3 & 3 & 3 & 4 \\
\hline T109 & NT & $;^{\mathrm{b}}$ & $2+$ & 1 & 3 & $22+$ & 1 & $1+^{\mathrm{b}}$ & 3 & $; 2^{\mathrm{b}}$ \\
\hline Terra E218 & 3 & 3 & 3 & 3 & 3 & 3 & 4 & 3 & 3 & 3 \\
\hline Terra SR204 & 3 & 3 & 3 & 3 & 3 & 3 & 3 & 3 & 3 & 3 \\
\hline Terra SR216 & 3 & 3 & 3 & 3 & 3 & 3 & 3 & 3 & 4 & 3 \\
\hline Terral TV 8555 & NT & ; & ; & ; & ; & ; & ; & ; & ; & ; \\
\hline Terral TV 8768 & NT & ; & ; & ; & ; & ; & ; & $; 1$ & $; 1$ & 1 \\
\hline Terral TV 8825 & NT & ; & ; & ; & ; & ; & ; & ; & ; & ; \\
\hline Terral TVX8670 & NT & ; & ; & ; & ; & ; & ; & ; & ; & 1 \\
\hline TW94315 & $; 1^{\mathrm{b}}$ & 3 & 3 & 3 & 3 & 3 & 3 & 3 & 3 & 3 \\
\hline TX87-20 & NT & $2^{\mathrm{b}}$ & 1 & 2 & 3 & 1 & $2+$ & $1^{\mathrm{b}}$ & 3 & $1^{b}$ \\
\hline TX91-13 & NT & ; & ; & ; & ; & ; & ; & ; & 2 & ; \\
\hline USG3408 & NT & ; & ; & ; & ; & $2+$ & 2 & $3-$ & 3 & 2 \\
\hline USG EXP 97-4 & NT & 3 & 3 & $; \mathrm{b}$ & 3 & 3 & $;^{\mathrm{b}}$ & 3 & 3 & 3 \\
\hline USG3209 & NT & ; & ; & ; & ; & ; & ; & 1 & 1 & 2 \\
\hline VA96-54-326 & NT & 3 & 1 & $2+$ & 3 & 3 & $2+$ & 3 & 3 & $; 1^{\mathrm{b}}$ \\
\hline VA97W-375 & NT & ; & ; & ; & ; & ; & ; & ; & 2 & ; \\
\hline Wakefield & NT & 3 & 1 & 1 & 3 & 3 & $; 1$ & 3 & 4 & 3 \\
\hline Wilfarm 488 & 3 & 3 & 3 & 3 & 3 & 3 & 3 & 3 & 3 & 3 \\
\hline
\end{tabular}

genes were not indicated as possibly present for these lines in Table 4.

Of the $L r$ genes identified as present among the 116 wheat lines, $\operatorname{Lrll}$ was the most frequent $(34.5 \%)$, followed by $\operatorname{Lr} 10$ and 3 (25.8 and $23.3 \%$, respectively) (Table 5). Genes $\operatorname{Lr} 9,26,2 a$, and 24 were present in 19.8 to $12.9 \%$ of the lines, and genes $L r 20,14 a, 2 c, 3 k a, 23,18$, and 1 were present in 0.9 to $7.7 \%$ of the lines. Of the genes identified as possibly present, Lr10 was the most frequent $(37.9 \%)$, followed by $L r l$ and 3 (35.3\% each). Genes Lr3ka, 14a, 20, 30, 28, 2c, 23, and 15 were possibly present in 18.1 to $29.3 \%$ of the lines, and genes $\operatorname{Lr} 18,24,11$, and $2 a$ were possibly present in 1.7 to $12.1 \%$ of the lines. Gene $\operatorname{LrlO}$ was the most frequently identified gene $(63.7 \%)$ when results were summarized across the present and possibly present categories. Genes $\operatorname{Lr} 9$ and 26 were only postulated to be present and never as possibly present. On the other hand, $L r 15,28$, and 30 were postulated to be only possibly present.

Of the 116 lines, 54 lines were found to have unidentified $L r$ genes (Table 3 ). The number of resistant reactions attributed to unidentified $L r$ genes ranged from 1 to 12 among lines with unidentified $L r$ genes. Lines SC921299 and SC921285 had the most resistant reactions attributed to unidentified $L r$ genes: 10 and 12, respectively. All 23 races were able to detect unidentified genes, and the number of resistant reactions attributed to unidentified $\mathrm{Lr}$ genes ranged from 1 to 21 among the races. Races MBMN, PNMT, and MFMP detected the most resistant reactions attributed to unidentified $L r$ genes, 17, 19, and 21 , respectively. Lines with identical responses to the races likely have the same unidentified $\mathrm{Lr}$ gene. For example, Pioneer 26R24, G60232, and TW94315 were sus- ceptible to all races tested except for resistant reactions caused by race BBBB; EK 156, F322W, IL94-2894, and MO94-317 had resistant reactions caused by race LBCS; and $\mathrm{OH} 552$ and Stine 950455 had resistant reactions caused by races PNMT and MFMP.

Gene $L r 14 a$ was postulated in only two lines, Dixie 911 and Stine 455 (Table 4). These two lines were susceptible to all races used in this study with the exception of BBBB, which produced an intermediate infection type $(22+)$ at $22 / 18^{\circ} \mathrm{C}$. Subsequent tests with races avirulent on $\operatorname{Lr} 14 a$ at constant $18^{\circ} \mathrm{C}$ indicated the presence of Lr14a.

Infection types produced by all races avirulent on isolines with $L r 1,9,10,16$, 24 , or 26 were never higher than IT $1+$ (Table 2) when inoculated onto these isolines. Races avirulent on LrII or Lrl8 produced infection types that ranged from $; 1$ 


\begin{tabular}{|c|c|c|c|c|c|c|c|c|c|c|c|c|}
\hline \multicolumn{13}{|c|}{ Race } \\
\hline MCRN & MFMP & MGMN & MGBN & PDLM & PNMT & SBDB & ТВРМ & TCRN & TDRP & TFRP & TLGM & TLRT \\
\hline 3 & $;^{\mathrm{b}}$ & $2+^{b}$ & $2+^{b}$ & 3 & $j^{\mathrm{b}}$ & 1 & 3 & 3 & 4 & 3 & 3 & 3 \\
\hline 3 & $;^{\mathrm{b}}$ & 3 & 3 & 3 & 1 & ; & 3 & 3 & 3 & 3 & 3 & 3 \\
\hline 3 & 2 & 1 & $2+$ & $1 ;$ & $2+$ & 1 & ;1 & 3 & 3 & 4 & 4 & 3 \\
\hline 3 & 3 & 3 & $1^{\mathrm{b}}$ & 3 & $1^{\mathrm{b}}$ & 3 & 3 & 3 & $2+^{b}$ & 4 & 4 & 3 \\
\hline 3 & 2 & ; b & ; b & ; & $1^{\mathrm{b}}$ & 1 & ; & 3 & 3 & 3 & ; & 3 \\
\hline 3 & 3 & $1^{\mathrm{b}}$ & 3 & 3 & 3 & 3 & 3 & 3 & $2^{b}$ & 4 & 4 & 3 \\
\hline 3 & 3 & 3 & 3 & NT & 3 & 3 & NT & 3 & 3 & 4 & 4 & 3 \\
\hline 3 & $1^{\mathrm{b}}$ & 1 & 1 & $; 1$ & ; & 1 & $; 1$ & 3 & 3 & 3 & 3 & 3 \\
\hline ; & $0^{\mathrm{b}}$ & ; & 1 & 0 & $;^{b}$ & ; & ; & 1 & $1^{b}$ & $2+$ & 1 & $1+^{b}$ \\
\hline 3 & 0 & 1 & ; & ; & ;12- & ; & ; & 3 & 4 & 3 & 3 & 3 \\
\hline 3 & $2+$ & ; & ; & NT & ; & 1 & NT & 3 & 1 & 3 & ; & 1 \\
\hline 3 & $1^{\mathrm{b}}$ & ;1 & 1 & $; 1$ & $1^{\mathrm{b}}$ & $2+$ & ; & 3 & 3 & $2^{b}$ & 3 & 3 \\
\hline 3 & 3 & 3 & 3 & NT & 3 & 3 & NT & 3 & 4 & 3 & 3 & 3 \\
\hline 3 & $1+2$ & 1 & 1 & $; 1$ & $12^{\mathrm{b}}$ & ;0 & $; 1$ & 3 & 3 & 3 & 4 & 3 \\
\hline 1 & 3 & ; & 1 & NT & $2+$ & ; & NT & 1 & 1 & 3 & ; & 1 \\
\hline 3 & 3 & $1^{\mathrm{b}}$ & 3 & $0^{\mathrm{b}}$ & 3 & 3 & ; & 3 & 3 & 3 & 3 & 3 \\
\hline 3 & $0^{\mathrm{b}}$ & ;b & ; b & ; & $1^{\mathrm{b}}$ & $0^{\mathrm{b}}$ & ; & 3 & 3 & 4 & 3 & 3 \\
\hline$; 2+$ & 3 & ; & $1 ;$ & NT & 1 & ; & NT & 1 & 1 & 4 & ; & 1 \\
\hline ; & ; & ; & $2+$ & NT & $2+$ & ; & NT & 3 & 3 & 3 & 4 & 3 \\
\hline $1^{\mathrm{b}}$ & 3 & $2++^{b}$ & $1^{\mathrm{b}}$ & 3 & 3 & $1^{\mathrm{b}}$ & 3 & 3 & $1^{\mathrm{b}}$ & $1^{\mathrm{b}}$ & $1^{\mathrm{b}}$ & 3 \\
\hline $1^{b}$ & ;b & 3 & $1^{\mathrm{b}}$ & 3 & $3+$ & $1^{\mathrm{b}}$ & 3 & 3 & 3 & $1^{b}$ & 3 & 3 \\
\hline $1^{\mathrm{b}}$ & $; 1^{\mathrm{b}}$ & 1 & 2 & $; 1$ & $; 1^{\mathrm{b}}$ & $2+$ & ; & 3 & 3 & 4 & $1^{\mathrm{b}}$ & 3 \\
\hline 3 & 3 & ; & 1 & NT & 1 & 1 & NT & 1 & $2+$ & 3 & ; & 1 \\
\hline 3 & 3 & 3 & 3 & 3 & 3 & $2+$ & 3 & 3 & 3 & 3 & 4 & 3 \\
\hline 3 & 3 & 3 & 3 & $\mathrm{NT}$ & 3 & 3 & NT & 3 & 4 & 3 & 4 & 3 \\
\hline 3 & $1^{\mathrm{b}}$ & $1+$ & 1 & $; 1$ & $1^{\mathrm{b}}$ & $3-$ & ; & 3 & 4 & 3 & 4 & 3 \\
\hline 3 & 3 & 3 & 3 & NT & 3 & 3 & NT & 3 & 3 & 3 & 4 & 3 \\
\hline 3 & 3 & 3 & 3 & NT & 3 & 3 & NT & 3 & 3 & 3 & 4 & 3 \\
\hline 3 & 4 & 3 & 3 & NT & 3 & 3 & NT & 3 & 3 & 3 & 4 & 3 \\
\hline 3 & $;^{b}$ & 1 & 1 & $; 1$ & $1^{\mathrm{b}}$ & $2+$ & ; & 3 & 3 & 3 & 4 & 3 \\
\hline 3 & 3 & 3 & 3 & NT & 3 & 3 & NT & 3 & 4 & 3 & 4 & 3 \\
\hline 3 & 4 & 3 & 3 & NT & 3 & 3 & NT & 3 & 4 & 3 & 4 & 3 \\
\hline 3 & 4 & 3 & 3 & NT & 3 & 3 & NT & 3 & 4 & 3 & 4 & 3 \\
\hline ; & 3 & ; & ; & NT & 1 & ; & NT & ; & 1 & 3 & ; & ; \\
\hline 2 & 1 & ; & ; & NT & $1 ;$ & 1 & NT & 1 & 1 & 1 & ; & 1 \\
\hline ; & 3 & ; & $2+$ & NT & $2+$ & 1 & NT & ; & 4 & 4 & ; & $1 ;$ \\
\hline 3 & $0 ; \mathrm{b}$ & 1 & $2+$ & $; 1$ & ; & 1 & $; 1$ & $1^{b}$ & 1 & $1 ; \mathrm{b}$ & 1 & 1 \\
\hline 3 & 3 & 3 & 3 & NT & 3 & 3 & NT & 3 & 3 & 3 & 3 & 3 \\
\hline ; b & $1^{\mathrm{b}}$ & 1 & 1 & $; 1$ & $1^{\mathrm{b}}$ & 1 & ; & $1^{\mathrm{b}}$ & 3 & $1^{\mathrm{b}}$ & 3 & 3 \\
\hline$; 2+$ & - & $2+$ & $1 ;$ & NT & $; 2+$ & ;1 & NT & ; & 1 & 1 & ; & ; \\
\hline 3 & $1^{\mathrm{b}}$ & 1 & $1 ;$ & $; 1$ & 12 & 1 & ; & 3 & 4 & 4 & 4 & 3 \\
\hline 3 & 4 & 3 & 3 & 3 & 3 & ;b & 3 & 3 & 4 & 4 & 3 & 3 \\
\hline$; 1$ & 1 & ; & ; & ; & ; & $1 ;$ & ; & 3 & 1 & $1^{\mathrm{b}}$ & ; & ; \\
\hline 3 & 4 & $1^{b}$ & 3 & 3 & 3 & 1 & 3 & 3 & 3 & 3 & 3 & 3 \\
\hline ;2 & ;1 & ; & ; & 0 ; & ; & ; & 0 & 1 & 1 & 1 & ; & 1 \\
\hline 3 & $3+$ & ${ }^{b}$ & 3 & 3 & 4 & ; & 4 & 3 & 3 & 3 & 3 & 3 \\
\hline 3 & 4 & 3 & 3 & NT & 3 & 3 & NT & 3 & 4 & 4 & 4 & 3 \\
\hline
\end{tabular}

to $2+$ but were clearly avirulent on the appropriate isoline(s). However, races PDLM and TBPM that were homozygous avirulent for $\mathrm{Lrll}$ produced infection type ;1 or lower on TcLrl1.

\section{DISCUSSION}

Results of this study indicated that at least 14 named $L r$ genes and several unidentified $L r$ genes are responsible for racespecific seedling resistance to leaf rust among 116 contemporary soft red winter wheat cultivars and breeding lines. Genes Lrl1, 10, and 3 were the most commonly identified $(34.5,25.8$, and $23.3 \%$ of the lines, respectively), and these genes have also been commonly identified $(29.7,18.0$, and $16.2 \%$, respectively) among 111 older soft red winter wheat cultivars as summarized by Roelfs et al. (31). Genes $L r 2 a$, 9, 24 , and 26 were identified in more than $10 \%(13.8,19.8,12.9$, and $15.5 \%$, respec- tively) of the lines in this study, and in $10.8,18.9,6.3$, and $9 \%$, respectively, in the older soft red winter wheat cultivars (31). Virulence to these genes has been common in North America $(18,19,20)$.

Combinations of $L r$ genes contributed greatly to leaf rust resistance among the 116 lines in this study. Forty-four different combinations of $\mathrm{Lr}$ genes (excluding the group with only unidentified $L r$ genes) were identified (Table 4). Some of these combinations still provide protection against prevalent races of $P$. triticina in the field. The combination of $\operatorname{Lr} 9,24$, and 26 provided resistance to all races used in this study. Given that existing races can overcome combinations of $\operatorname{Lr} 9$ and $26, \operatorname{Lr} 9$ and 24, and $L r 24$ and 26, it seems likely that a race capable of overcoming the combination of $\operatorname{Lr} 9,24$, and 26 will occur eventually.

The unidentified genes could be known $L r$ genes such as $L r 3 b g, 14 b$, or $27+31$ that were not in the sets of isolines, adult-plant resistance genes such as $L r 13,34$ that are expressed somewhat in the seedling stage (2-4,6,29), undescribed $L r$ genes, or undescribed alleles of known $\mathrm{Lr}$ genes. Inclusion of isolines for $\mathrm{Lr} 3 \mathrm{bg}, 13,14 \mathrm{~b}, 27+31$ 34 , and $13+34$ in this study may have allowed some of these $L r$ genes to be identified or excluded.

The 1BL.1RS translocation was a reliable marker for $L r 26$. All lines reported to have the 1BL.1RS translocation (8) were postulated to have $L r 26$, and all lines postulated to have Lr26 had the 1BL.1RS translocation. The only inconsistency for postulating $\operatorname{Lr} 26$ was found in P86764RA1-4-2-7, which was subsequently determined to have mixed seeds for the 1BL.1RS translocation (B. Graybosch, personal communication) and for reaction to races avirulent to $L r 26$. Using the 1BL.1RS translocation as a marker for 
Lr26 facilitated postulating $L r$ genes for the four lines that were resistant to all races.

Genes $L r 3 k a, 18$, and 23 were identified to be present in low frequencies $(3.4,6.9$, and $3.4 \%$, respectively). Virulence was common to $L r 23$, and this gene was not considered useful (24). Although virulence to $L r 3 k a$ and 18 is common in North
America $(14,18)$, these genes had been considered useful in Australia (24) and as interacting with adult-plant resistance gene Lr34 in North America (7).

Gene $L r 14 a$ was postulated to be present only in Dixie 911 and Stine 455. This gene was reported to be difficult to detect due to its moderate reaction and hence epistatic effect of other genes with lower infection types (24). However, it appeared that Dixie 911 and Stine 455 had no other seedling genes that could be epistatic over Lrl4a. Virulence was common to $L r I 4 a$, and this gene has not been considered useful $(14,18,24)$.

Genes $\operatorname{Lr} 2 a$ and $2 c$ were identified as present in 13.8 and $3.4 \%$ of the lines, respectively, in this study. Gene Lr2a has

Table 4. Seedling $L r$ genes in contemporary soft red winter wheat cultivars and advanced breeding lines

\begin{tabular}{|c|c|}
\hline Seedling $L r$ genes $^{\text {a }}$ & Line \\
\hline \multicolumn{2}{|l|}{ No detectable $L r$ genes } \\
\hline None & $\begin{array}{l}\text { Caldwell, Delta Grow 3300, G41332, G41333, Stine 488, T104, T105, T106, Terra } \\
\text { SR204, Terra SR216, Terra E218, Wilfarm 488, IL91-15911 }\end{array}$ \\
\hline \multicolumn{2}{|r|}{ (1) } \\
\hline 1 & Armor 3235 \\
\hline $1,2 a, 2 c, 3$, and $/$ or 10,11 & Sabbe \\
\hline 1,10 & HT98-10033 \\
\hline $1,3,10,11$ & Pioneer 26R46 \\
\hline $2 a, 9(1,2 c, 3,10,11,15,23)$ & Agripro Shiloh, BL940026, Buckshot's DS91, GA90524E35, LA8513B1-7-B-1-4-2 \\
\hline $2 a, 9,18(1,2 c, 3,3 \mathrm{ka}, 10,11,14 a, 15,20,23,28,30)$ & APD95*8811-2, LA90144B16-3-2, LA904122F14-1-4 \\
\hline $2 a, 9,18$, or $11(1,2 c, 3,3 \mathrm{ka}, 10,14 a, 15,20,23,28,30)$ & NK Coker 9835 \\
\hline $2 a, 2 c, 3$, and/or 10 & NK Coker 9025 \\
\hline $2 a, 2 c, 24(1,3,3 k a, 10,14 a, 15,20,23,28,30)$ & GA88622E51 \\
\hline 3,10 & M95*3349 \\
\hline 3 and/or 10,11 & NK Coker 9543 \\
\hline $3 \mathrm{ka}, 18,26(1,3,10,15,20,23,28,30)$ & Terral TV 8768 \\
\hline $3 k a, 26(1,3,10,14 a, 15,28,30)$ & SS550 \\
\hline $9(1,2 c, 3,10,15,23)$ & APD95*8811-1, BL931167 \\
\hline $9,11(1,2 a, 2 c, 3,10,15,23)$ & Agripro Mason, LA9070G45-3-3-1, NC95-25707, NK Coker 9663 \\
\hline $9,11,18(1,2 a, 2 c, 3,3 \mathrm{ka}, 10,14 a, 15,20,23,28,30)$ & Dixie 2000, FFR 522W \\
\hline $9,24(1,2 c, 3,3 k a, 10,14 a, 15,18,20,23,28,30)$ & APD95-7763 \\
\hline $9,26(1,2 c, 3,3 k a, 10,14 a, 15,18,20,23,24,28,30)$ & TX91-13 \\
\hline $9,24,26\left({ }^{b}\right)$ & Agripro Marion, AP-D94-5282, NC94-7197, VA97W-375 \\
\hline 10 & Agripro Shelby, Florida 302, NK Coker 9704 \\
\hline 11,18 & Agripro Hickory \\
\hline $11,23,26(1,2 a, 2 c, 3,3 k a, 10,14 a, 15,20,24,28,30)$ & Agripro Foster, AGS2000, KY86C-127-3 \\
\hline $11,24,26(1,2 a, 2 c, 3,3 k a, 10,14 a, 15,20,23,28,30)$ & Agripro Patton \\
\hline $11,26(1,3,3 \mathrm{ka}, 10,14 a, 28,30)$ & Pioneer 26R61 \\
\hline $14 a$ & Dixie 911 , Stine 455 \\
\hline $24(1,3,10,14 a, 28)$ & Terral TV 8825 \\
\hline $24,26(1,3,3 \mathrm{ka}, 10,14 a, 15,20,23,28,30)$ & FFR 558W, Quantum 708, S9412192, Terral TV 8555 \\
\hline \multicolumn{2}{|l|}{ Known $L r$ genes plus one or more unidentified genes } \\
\hline $1,+$ & IL94-2894 \\
\hline $1,2 a, 3$, and/or $10,23,+(2 c, 11,15)$ & Florida 8868 \\
\hline 1,3, and/or $10,11,+$ & Jackson \\
\hline $1,3,11,+(10)$ & USG 3408 \\
\hline $1,3 \mathrm{ka}, 11,+(3,10,30)$ & P86364RA1-4-2-7 \\
\hline $2 a, 3$, and $/$ or $10,11,+(2 c)$ & GA881404E56 \\
\hline $2 a, 2 c, 3$, and/or $10,11,+$ & NK Coker 9184 \\
\hline $2 a, 11,26,+(1,2 c, 3,3 k a, 10,14 a, 28,30)$ & USG3209 \\
\hline $2 a, 11,24,+(1,2 c, 3,3 k a, 10,14 a, 15,20,23,28,30)$ & NK Coker 9152 \\
\hline $3,10,11,+$ & $\begin{array}{l}\text { Jaypee, Madison, LA87167D8-10-2, OH599, Stine 950455, T109, TX87-20, M95*2883, } \\
\text { Pioneer } 2548\end{array}$ \\
\hline $3,10,11,18,+$ & Pioneer 2684 \\
\hline $3,10,+$ & Cardinal \\
\hline $3,11,+$ & EK 114, OH 552, Pocahontas \\
\hline $3,11,+(10)$ & Delta King $1551 \mathrm{~W}$ \\
\hline $3,11,+(1,10)$ & Pioneer XW672 \\
\hline 3 and/or $10,11,+$ & SS36803 \\
\hline $3 k a, 24,+(1,3,10,14 a, 15,20,28,23,30)$ & HT98-10291 \\
\hline $3 k a, 11,26,+(1,3,10,14 a, 15,28,30)$ & Terral TVX8670 \\
\hline $10,+$ & AR 584A-3-1, OH 536, MO94-317, VA96-54-326, Wakefield \\
\hline $11,+$ & Roberts \\
\hline $20,+(15,28)$ & NC95-25305 \\
\hline
\end{tabular}

One or more unidentified genes

$+$

Agripro Mallard, Delta King 9027, Delta King 9051, Delta King 9121, EK 103, EK 156, F322W, G60232, M95*3330, OK91P648-41, P92227C5-1-1, IL94-6727, P88204RB1-21-6, Pioneer 26R24, Roane, SC921285, SC921299, TW94315, USG Exp 97-4

\footnotetext{
${ }^{a}$ Genes without parentheses were determined to be present by matching the infection type on the line with the infection type on the corresponding Thatcher isoline. Genes within parentheses were determined to be possibly present if the low infection type produced on the line by one or more races did not match the low infection type on the corresponding isoline. Epistatic effects prevented the definitive inclusion or exclusion of genes considered possibly present. + $=$ Unidentified gene, i.e., the gene was not in the set of 24 isolines. " 3 and /or 10" means either $L r 3$ or $L r 10$ or both were present.

${ }^{b}$ All the remaining $21 \mathrm{Lr}$ genes could be possibly present due to epistatic effects of the other three genes.
} 
been used largely in the north central United States (17) and in the southern United States (21), but it has been considered as having limited value if used alone (24). Since 1993, the frequency of virulence to $L r 2 a$ was much lower than that to $L r 1,3,10$, and 11 (18,19). Gene $L r 2 c$ was detected neither in hard red winter wheat (26) nor in older soft red winter wheat (31). However, in 2000, virulence to $2 c$ was common in soft red winter wheat growing regions in the United States (18), and the virulence frequency to $L r 2 c$ was higher than to $L r 2 a$, and therefore, $L r 2 c$ was considered to be less useful than $L r 2 a$ $(5,18,24)$.

Although genes $\operatorname{Lr15}, 20$, and 28 were identified as possibly present in several lines in this study, these genes are not likely to be important components of the genetic basis for leaf rust resistance in soft red winter wheat. Genes $\operatorname{Lr} 15,20$, and 28 have never been postulated in wheat cultivars. $L r 20$ has only been postulated in one line (NC95-25305) in this study, one older soft red winter wheat cultivar (Converse [31]), and a few cultivars from the United Kingdom (37). Furthermore, virulence for these genes is common $(14,24)$, and the genes provide only moderate resistance to most of the avirulent races (Table 2).

Genes Lrl6 and 17 that were postulated among hard red winter wheat lines (26) were not detected in soft red winter wheat lines in this study. Of the older soft red winter wheat summarized by Roelfs et al. (31), Lrl7 was not present and Lrl6 was only in T63. Although virulence to Lr16 and 17 is prevalent in North America, Lrl6 was reported to interact with $\operatorname{Lrl3}$ to give enhanced resistance (35). Kolmer (14) did not find virulence to $L r 16$ or 17 in $P$. triticina isolates from the South Atlantic region, and Long et al. (18) detected no virulence to Lrl6 in 2000 in soft red winter wheat growing regions in United States.

Isolines with genes $L r 21,32,36,38$, and 39 were resistant to all races used in this study. These genes have not been widely exploited (24) and could be useful in soft red winter wheat.

Among soft red winter wheat lines that were common to this study and the summary by Roelfs et al. (31), results on the postulated genes largely agreed. For example, Roelfs et al. (31) postulated $L r 26$ in AP-D94-5282, VA97W-375, AGS2000, Agripro Foster, TX91-13, and SS550. In this study, however, other genes were identified in addition to $\operatorname{Lr} 26$ (Table 4). There were disagreements with Roelfs et al. (31) for $L r$ genes in Agripro Hickory ( $L r 2 a, 18)$ and $\mathrm{OH} 599$ (Lr26). In this study, there was no indication for the presence of $L r 2 a$ in Agripro Hickory, but several races supported the presence of Lrl1. Likewise, there was no indication for the presence of Lr26 in $\mathrm{OH} 599$. OH 599 and lines such as SS36803 that were reported to have the 1AL.1RS translocation (8) did not display the low infection type that matches $L r 26$.

Florida 302, which was described to have $L r 2 a, 10$, and 11 by McIntosh et al. (24), and LrIO+ by Roelfs et al. (31), was postulated to have only $\operatorname{Lr} 10$ in this study. Only races avirulent on $\mathrm{Lr} 10$ displayed low infection types (Table 3). All races avirulent on Lrll, including the two known homozygous avirulent races, produced susceptible reactions. None of the races avirulent on $\operatorname{Lr} 2 a$ indicated presence of $L r 2 a$ in Florida 302. These results were confirmed with two additional sources of Florida 302 seed.

Heterozygosity for avirulence is common among isolates of P. triticina (34), and it is likely that some isolates used in the current study were homozygous for avirulence and others were heterozygous. This heterozygosity coupled with partial dominance for avirulence may explain the wide range of avirulent infection types produced on isolines with certain $L r$ genes. The only genetic study of dominance for avirulence in $P$. triticina (15) determined that avirulence for genes $L r 2 a, 2 c, 3 k a, 11$, and 30 was partially dominant and that virulence for genes $\operatorname{Lr} 3$ and 17 was fully dominant. These conclusions are supported by infection type data in the current study (Table 2). Avirulent infection types on isolines with $\operatorname{Lr} 3$ and 17 were relatively uniform, indicating that homozygous and heterozygous isolates probably produced similar infection types, indicating avirulence is fully dominant. Avirulent infection types on isolines with $L r 2 a, 2 c, 3 k a, 11$, and 30 ranged from ; to 2 or $2+$, indicating that homozygous isolates likely are responsible for the lowest infection types and heterozygous isolates likely are responsible for the intermediate infection types. This relationship was confirmed with two isolates (PDLM and TBPM) known to be homozygous avirulent for Lr11. Avirulence for genes $L r 1,9,10,14$, 16,24 , and 26 appeared to be fully dominant because all avirulent races produced similar infection types on isolines with these genes. Avirulence for genes $\operatorname{Lr} 15,18$, 20 , and 23 appeared to be partially dominant because avirulent races produced a range of infection types. Although genetic studies would be required to confirm whether avirulence to these genes was fully or partially dominant, comparing infection types on each isoline appeared to provide an indication of whether avirulence was fully or partially dominant. It would be advantageous to use races that are homozygous avirulent to postulate $\mathrm{Lr}$ genes that interact with avirulence genes that are known or suspected to be partially dominant. This is the first report to implicate partial dominance for avirulence as a contributing factor to the range of avirulent infection types produced by particular races on particular isolines and lines in gene postulation studies.

The combination of partial dominance for avirulence and temperature sensitivity are likely responsible for the large range of low infection types (; to 3-) and the difficulty of postulating $\mathrm{LrIl}$ as reported by McIntosh et al. (24). Results of this study indicated that $2 r 11$ is relatively easy to postulate by using homozygous avirulent isolates at low $\left(17^{\circ} \mathrm{C}\right)$ constant temperature. However, additional races that are homozygous avirulent for $\mathrm{Lrll}$ are needed in order to overcome the epistatic effects of other resistance genes and allow definitive postulation for Lrll in more wheat lines. Similarly, the combination of partial dominance for avirulence and temperature sensitivity of $\operatorname{Lr} 18$ probably was responsible for the range of infection types produced on TcLr18. Tests at low temperature could have been simplified by choosing only one low temperature, and $17^{\circ} \mathrm{C}$ likely would work well for detecting all three (Lr14a, 11, and 18) temperature-sensitive genes.

Table 5. Number and percentage of the 116 soft red winter wheat lines that were postulated to have specific leaf rust resistance genes

\begin{tabular}{|c|c|c|c|c|c|c|c|c|c|c|c|c|c|c|c|c|c|c|}
\hline & & \multicolumn{17}{|c|}{$L r$ gene $^{a}$} \\
\hline & & 1 & $2 a$ & $2 c$ & 3 & $3 k a$ & 9 & 10 & 11 & $14 a$ & 15 & 18 & 20 & 23 & 24 & 26 & 28 & 30 \\
\hline \multirow{2}{*}{ Present $^{\mathrm{b}}$} & No. & 9 & 16 & 4 & 27 & 4 & 23 & 30 & 40 & 2 & 0 & 8 & 1 & 4 & 15 & 18 & 0 & 0 \\
\hline & $\%$ & 7.7 & 13.8 & 3.4 & 23.3 & 3.4 & 19.8 & 25.8 & 34.5 & 1.7 & 0 & 6.9 & 0.86 & 3.4 & 12.9 & 15.5 & 0 & 0 \\
\hline \multirow{2}{*}{$\begin{array}{l}\text { Possibly } \\
\text { present }^{\mathrm{c}}\end{array}$} & No. & 41 & 14 & 31 & 41 & 21 & 0 & 44 & 10 & 24 & 34 & 2 & 24 & 32 & 4 & 0 & 30 & 29 \\
\hline & $\%$ & 35.3 & 12.1 & 26.7 & 35.3 & 18.1 & 0 & 37.9 & 8.6 & 20.6 & 29.3 & 1.7 & 20.6 & 27.6 & 3.4 & 0 & 25.9 & 25 \\
\hline \multirow{2}{*}{ Total $^{\mathrm{d}}$} & No. & 50 & 30 & 35 & 68 & 25 & 23 & 74 & 50 & 26 & 34 & 10 & 25 & 36 & 19 & 18 & 30 & 29 \\
\hline & $\%$ & 43.1 & 25.9 & 30.1 & 58.6 & 21.5 & 19.8 & 63.7 & 43.1 & 22.3 & 29.3 & 8.6 & 21.5 & 31 & 16.3 & 15.5 & 25.9 & 25 \\
\hline
\end{tabular}

${ }^{a}$ Resistance genes $L r 16$ and 17 were not identified as present or possibly present, and genes $L r 21,32,36,38$, and 39 could not be postulated.

${ }^{\mathrm{b}} \mathrm{Lr}$ genes identified by matching infection type on wheat lines with the infection type on the corresponding isoline.

${ }^{\mathrm{c}} \mathrm{Lr}$ genes could not be excluded from a line but could not be identified by matching infection types on the corresponding isoline because of epistatic interactions among $L r$ genes.

${ }^{\mathrm{d}}$ Sum of present and possibly present. 
Approximately $97 \%$ of the contemporary soft red winter wheat cultivars and breeding lines in this study were vulnerable at the seedling stage to one or more of the races of $P$. triticina, and only four lines were resistant to all races used. Nearly $33 \%$ of the lines in this study were identified with three or more $\mathrm{Lr}$ genes compared with only $9 \%$ in older soft red winter wheat lines (31). Compared with older soft red winter wheat lines, contemporary soft red winter wheat lines had more combinations of $\operatorname{Lr}$ genes, suggesting soft red winter wheat breeders have been stacking genes to obtain resistance to leaf rust.

\section{ACKNOWLEDGMENTS}

We thank David Long and Jim Kolmer, from USDA-ARS, Cereal Disease Laboratory, for providing pathogen isolates, seeds of isolines, advice, and information; Brent McCallum from Cereal Research Centre Agriculture and Agri-Food, Canada, for providing pathogen isolates; and Ravi Singh from CIMMYT for his useful comments and suggestions. Technical support from the wheat pathology team of University of Arkansas and financial support from the Arkansas Wheat Promotion Board are gratefully appreciated.

\section{LITERATURE CITED}

1. Browder, L. E. 1980. A compendium of information about named genes for low reaction to Puccinia recondita in wheat. Crop Sci. 20:775-779.

2. Dyck, P. L. 1987. The association of a gene for leaf rust resistance with the chromosome 7D suppressor of stem rust resistance in common wheat. Genome 29:467-469.

3. Dyck, P. L. 1991. Genetics of adult plant leaf rust resistance and leaf tip necrosis in wheat. Crop Sci. 32:874-878.

4. Dyck, P. L., and Johnson, R. 1983. Temperature sensitivity of genes for resistance in wheat to Puccinia recondita. Can. J. Plant Pathol. 5:229-234.

5. Dyck, P. L., and Samborski, D. J. 1974. Inheritance of virulence in Puccina recondita on alleles at $L r 2$ locus for resistance in wheat. Can. J. Genet. Cytol. 16:323-332.

6. Dyck, P. L., and Samborski, D. J. 1979. Adultplant resistance in PI 250413, an introduction of common wheat. Can. J. Genet. Cytol. 24:273-283.

7. German, S. E., and Kolmer, J. A. 1992. Effect of gene $L r 34$ in the enhancement of resistance to leaf rust of wheat. Theor. Appl. Genet. 84:97-105.

8. Graybosch, B. 2001. Compendium of wheat lines carrying rye chromosome arm 1RS. U.S. Dep. Agric. Published online. Accessed November 5, 2002.

9. Johnson, R. 1984. A critical analysis of durable resistance. Annu. Rev. Phytopathol. 22:309-330.
10. Jones, D., and Clifford, B. C. 1978. Cereal Diseases and Control. BASF, England, UK.

11. Kolmer, J. A. 1992. Virulence heterozygosity and gametic phase disequilibria in two populations of Puccinia recondita. Heredity 68:505513.

12. Kolmer, J. A. 1996. Genetics of resistance to wheat leaf rust. Annu. Rev. Phytopathol. 34:435-455.

13. Kolmer, J. A. 1997. Virulence in Puccinia recondita f. sp. tritici isolates from Canada to genes for adult-plant resistance to wheat leaf rust. Plant Dis. 81:267-271.

14. Kolmer, J. A. 2002. Virulence phenotypes of Puccinia triticina in the South Atlantic States in 1999. Plant Dis. 86:288-291.

15. Kolmer, J. A., and Dyck, P. L. 1994. Gene expression in the Triticum aestivum-Puccinia recondita $\mathrm{f}$. sp. tritici gene-for-gene system. Phytopathology 84:437-440.

16. Long, D. L., and Hughes, M. E. 2001. Small Grain Losses to Rust. U.S. Dep. Agric. Res. Serv. Cereal Dis. Lab. Online, Publication CDL-EP \#007. Accessed November 7, 2002.

17. Long, D. L., and Kolmer, J. A. 1989. A North American system of nomenclature for Puccinia recondita f. sp. tritici. Phytopathology 79:525-529.

18. Long, D. L., Kolmer, J. A., Leonard, K. J., and Hughes, M. E. 2002. Physiologic specialization of Puccinia triticina on wheat in the United States in 2000. Plant Dis. 86:981-986.

19. Long, D. L., Leonard, K. J., and Roberts, J. J. 1998. Virulence and diversity of wheat leaf rust in the United States in 1993 to 1995. Plant Dis. 82:1391-1400.

20. Long, D. L., Schafer, J. F., Roelfs, A. P., and Roberts, J. J. 1989. Virulence of Puccinia recondita f. sp. tritici in the United States in 1987. Plant Dis. 73:294-297.

21. Marshall, D. 1988. Characteristics of the 19841985 wheat leaf rust epidemic in central Texas. Plant Dis. 72:239-241.

22. Martens, J. W., and Dyck, P. L. 1989. Genetics of resistance to rust in cereals from a Canadian perspective. Can. J. Plant Pathol. 11:78-85.

23. McIntosh, R. A. 1992. Pre-emptive breeding to control wheat rust. Euphytica 63:103-113.

24. McIntosh, R. A., Wellings, C. R., and Park, R. F. 1995. Wheat Rusts: An Atlas of Resistance Genes. Kluwer Academic Publishers, London.

25. McVey, D.V. 1992. Genes for resistance in international winter wheat nurseries XII through XVII. Crop Sci. 32:891-895.

26. McVey, D. V., and Long, D. L. 1993. Genes for leaf rust resistance in hard red winter wheat cultivars and parental lines. Crop Sci. 33:13731381

27. Modawi, R. S., Browder, L. E., and Heyne, E. G. 1985. Use of infection type data to identify genes for low reaction to Puccinia recondita in several winter wheat cultivars. Crop Sci. 25:913.

28. Park, R. F., Burdon, J. J., and Jahoor, A. 1999. Evidence for somatic hybridization in nature in Puccinia recondita $\mathrm{f}$. sp. tritici, the leaf rust pathogen of wheat. Mycol. Res. 103:715-723.

29. Pretorius, Z. A., Wilcoxson, R. D., Long, D. L., and Schafer, J. F. 1984. Detecting leaf rust resistance gene Lr13 in seedlings. Plant Dis. 68:585-586

30. Roelfs, A. P. 1988. Resistance to leaf and stem rust in wheat. Pages 10-22 in: Breeding Strategies for Resistance to the Rusts of Wheat. N. W. Simmonds and S. Rajaram, ed. CIMMYT, Mexico D.F.

31. Roelfs, A. P., Hughes, M. E., and Long, D. L. 2000. Rust resistance genes in wheat lines and cultivars. U.S. Dep. Agric. Res. Serv. Cereal Dis. Lab. Online, Publication CDL-EP \#006. Accessed November 7, 2002.

32. Samborski, D. J. 1963. A mutation in Puccinia recondita Rob. ex Desm. f. sp. tritici to virulence on Transfer, Chinese Spring $\times$ Aegilops umbellulata Zhuck. Can. J. Bot. 41:475-479.

33. Samborski, D. J. 1985. Wheat leaf rust. Pages 39-59 in: The Cereal Rusts. Vol. II. Diseases, Distribution, Epidemiology and Control. A. P. Roelfs and W. R. Bushnell, ed. Academic Press, Orlando, FL.

34. Samborski, D. J., and Dyck, P. L. 1968. Inheritance of virulence in wheat leaf rust on the standard differential wheat varieties. Can. J. Genet. Cytol. 10:24-32.

35. Samborski, D. J., and Dyck, P. L. 1982. Enhancement of resistance to Puccinia recondita by interactions of resistance genes in wheat Can. J. Bot. 37:1153-1155.

36. Shang, H. S., Dyck, P. L., and Samborski, D. J. 1986. Inheritance of resistance to Puccinia recondita in a group of resistant accessions of common wheat. Can. J. Plant Pathol. 8:123131.

37. Singh, D., Park, R. F., and McIntosh, R. A. 2001. Postulation of leaf (brown) rust resistance genes in 70 wheat cultivars grown in the United Kingdom. Euphytica 120:205-218.

38. Singh, R. P. 1993. Resistance to leaf rust in 26 Mexican wheat cultivars. Crop Sci. 33:633 637.

39. Singh, R. P., Chen, W. Q., and He, Z. H. 1999 Leaf rust resistance of spring, facultative, and winter wheat cultivars from China. Plant Dis. 83:644-651.

40. Singh, R. P., and Rajaram, S. 1991. Resistance to Puccinia recondita $\mathrm{f}$. sp tritici in 50 Mexican bread wheat cultivars. Crop Sci. 31:14721479

41. Stakman, E. C., Stewart, D. M., and Loegering, W. Q. 1962. Identification of physiological races of Puccinia graminis var. tritici. U.S Dep. Agric. Agric. Res. Serv. Bull. E617. (Revised 1962)

42. Statler, G. D. 1984. Probable genes for leaf rust resistance in several hard red spring wheats. Crop Sci. 24:883-886.

43. Zeller, F. J. 1973. 1B/1R wheat-rye chromosome substitutions and translocations. Pages 209-221 in: Proc. Int. Wheat Genet. Sympos. 4th. E. Sears and L. M. S. Sears, eds. Agricultural Experiment Station, University of Missouri, Columbia. 